\title{
Study on Re-Energization Capability of a Hybrid Windfarm under a Microgrid-based Restoration Strategy
}

\author{
Duncan Maina ${ }^{1}$ and Nirmal-Kumar Nair ${ }^{2}$ \\ ${ }^{1}$ The University of Auckland \\ ${ }^{2}$ University of Auckland
}

February 1, 2021

\begin{abstract}
Under a microgrid based (bottom-up) restoration strategy, considering a disaster related outage, the local generation is required to energize and supply the unaffected part of the network. Considering $100 \%$ renewable generation, only hydro based generation systems, if well equipped, can be able to blackstart and re-energize the network. Wind Energy Conversion Systems (WECSs) have been restricted to the latter stages of restoration due to their source intermittency and non-dispatchability and in order for them to participate in the initial restoration stages, voltage and frequency support auxiliary devices are required. This paper investigates the capability of a hybrid windfarm to participate in the initial stages of restoration similar to a conventional blackstart unit: Re-energization of the various network components and pick up of load. The auxiliary equipment in this case is a dump load to absorb excess power produced by the windfarm and a synchronous condenser to provide a stable voltage reference required for normal operation of the WECS. Firstly, the nominal range of operation is determined with an additional pitch control mode linking the dump load power to individual WECSs introduced for frequency control. Flicker and harmonics are investigated in determination of the hosting capacity. Studies are undertaken to investigate energization of transformers, underground cables, overhead lines and other non-blackstart units (including other WECSs). Consideration is given to Type 1 and Type 3 WECSs to investigate the capability of a non-inverter and inverter based WECS. MATLAB/Simulink has been used as the simulation platform due to its modelling flexibility.
\end{abstract}

Study on Re-Energization Capability of a Hybrid Windfarm under a Microgrid-based Restoration Strategy Duncan Kaniaru Maina ${ }^{1}$, Nirmal-Kumar C Nair ${ }^{1}$

${ }^{1}$ Department of Electrical, Computer and Software Engineering, University of Auckland, Private Bag 92019, Auckland 1142, Auckland, New Zealand.

Correspondence

Duncan Kaniaru Maina, Email: dmai810@aucklanduni.ac.nz

Summary: Under a microgrid based (bottom-up) restoration strategy, considering a disaster related outage, the local generation is required to energize and supply the unaffected part of the network. Considering $100 \%$ renewable generation, only hydro based generation systems, if well equipped, can be able to blackstart and re-energize the network. Wind Energy Conversion Systems (WECSs) have been restricted to the latter stages of restoration due to their source intermittency and non-dispatchability and in order for them to participate in the initial restoration stages, voltage and frequency support auxiliary devices are required. This paper investigates the capability of a hybrid windfarm to participate in the initial stages of restoration similar to a conventional blackstart unit: Re-energization of the various network components and pick up of load. The auxiliary equipment in this case is a dump load to absorb excess power produced by the windfarm and a synchronous condenser to provide a stable voltage reference required for normal operation of the WECS. 
Firstly, the nominal range of operation is determined with an additional pitch control mode linking the dump load power to individual WECSs introduced for frequency control. Flicker and harmonics are investigated in determination of the hosting capacity. Studies are undertaken to investigate energization of transformers, underground cables, overhead lines and other non-blackstart units (including other WECSs). Consideration is given to Type 1 and Type 3 WECSs to investigate the capability of a non-inverter and inverter based WECS. MATLAB/Simulink has been used as the simulation platform due to its modelling flexibility.

Keywords: DFIG, Network Re-energization, Range of Operation, SCIG, Hybrid Mode.

\section{Introduction}

There are 2 common approaches to restoration after a blackout: Bottom-up and top-down [1]. Bottom-up approach, also referred to as microgrid based restoration, relies on local generation with blackstart capability to re-energize the network while top-down approach relies on interconnecting lines from blackout-unaffected regions to re-energize the network. Commonly used blackstart generators in the case of microgrid formation are hydro and diesel based. Thermal based generation, if equipped with load rejection capabilities [2], can be able to re-energize the network but it depends on how long the generator has been on no-load. Activities related to network re-energization include component (transformer, overhead lines, underground cables) re-energization, cranking up of non-blackstart units (motor energization) and load pickup [3].

For the last 2 decades there has been a continuous increase in wind and solar based generation, and this is in aiming for $100 \%$ renewable energy generation by 2050 [4]. At the same time, the globe is also seeing an increase in disasters causing damage to the electricity and interdependent infrastructure. With disaster related outages, the trajectory of the disaster remains unknown until it happens and if a $100 \%$ renewable generation is assumed, there is need to investigate the role of non-hydro based renewable energy sources if they have been left unscathed. Currently, wind and solar based generation systems are utilized only after the core grid is stable and only to assist in picking up load. Focus of this study will be on wind-based generation systems/wind energy conversion systems (WECSs).

Research on the role of WECSs during restoration has been reviewed in [5], together with other new power system technologies. Focus on research has been on the optimal use of windfarms during the load pickup stage [6-9]. Use of WECSs in earlier stages using support of either energy storage elements, voltage support devices or Voltage Source Converter based High Voltage Direct Current (VSC-HVDC) has been proposed in [10-17]. [18] provides a detailed analysis by identification of limitations of the use of Type 3 WECSs in restoration from a voltage and frequency standpoint, and the control methodology required to enable it to blackstart. No research, as per knowledge of the author, has been done on investigation of hybrid windfarms in re-energizing the network and this will be the focus of this study.

A comprehensive review of different standalone WECSs has been provided in [19]. Gearless-drive PMSG and geared-drive SCIG have been deemed as the best schemes in terms of performance. In order to ensure a successful standalone WECS scheme, there must be a stable voltage reference and an energy storage element. The term 'standalone' is used when the auxiliary elements are located within the WECS. In this study, the auxiliary equipment (synchronous condenser and dump load) are located at the windfarm collector point thus the term 'hybrid' is used. A synchronous condenser (SC) is used to provide a stable voltage reference and required reactive power while a dump load is used to absorb the excess energy produced by the windfarm. Consideration is only given to Type 1 and Type 3 WECSs as they depict a non-inverter and inverter-based technology respectively. In order to focus on the windfarm response, the instances of re-energization and load pickup are assumed to occur when there is sufficient power from the WECSs.

The remainder of this paper is organized as follows: Section 2 describes the test system and component models used. Section 3 firstly discusses the nominal range of operation whilst looking at the different power quality issues afterwhich the results of the different network re-energization related activities are discussed. A brief conclusion is provided in section 4 .

2. Test System Description 
The system under study is as shown in Fig. 1. It is a subsection of a windfarm in which there are multiple strings each of 10 WECSs. The capacity of the sub-section of the windfarm operational (WECSs connected) is assumed to be approximately 9MW and as previously mentioned, the WECSs can either be of Type 1 or Type 3. A comparison will be provided between the two. This layout is applicable to an offshore windfarm and for it to be applicable for an onshore windfarm the HV submarine cable is substituted by an overhead line.

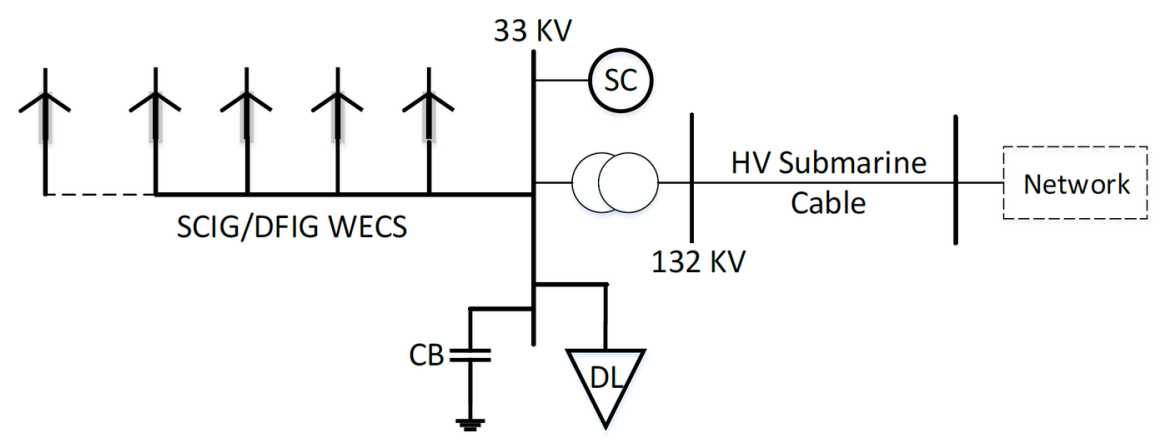

Figure 1. Test System

\subsection{Type 1 WECS}

Type 1 WECS is based on the squirrel cage induction generator (SCIG). In this study, each SCIG is rated at 2.3MW and in order to achieve an approximately 9MW capacity windfarm, 4 WECSs are considered operational. Fig. 2 shows the general schematic of Type 1 WECS. A simple 4 staged resistive starter [20] has been used to limit the inrush currents associated during their synchronization to the system. Parameters of the SCIG are obtained in [21].

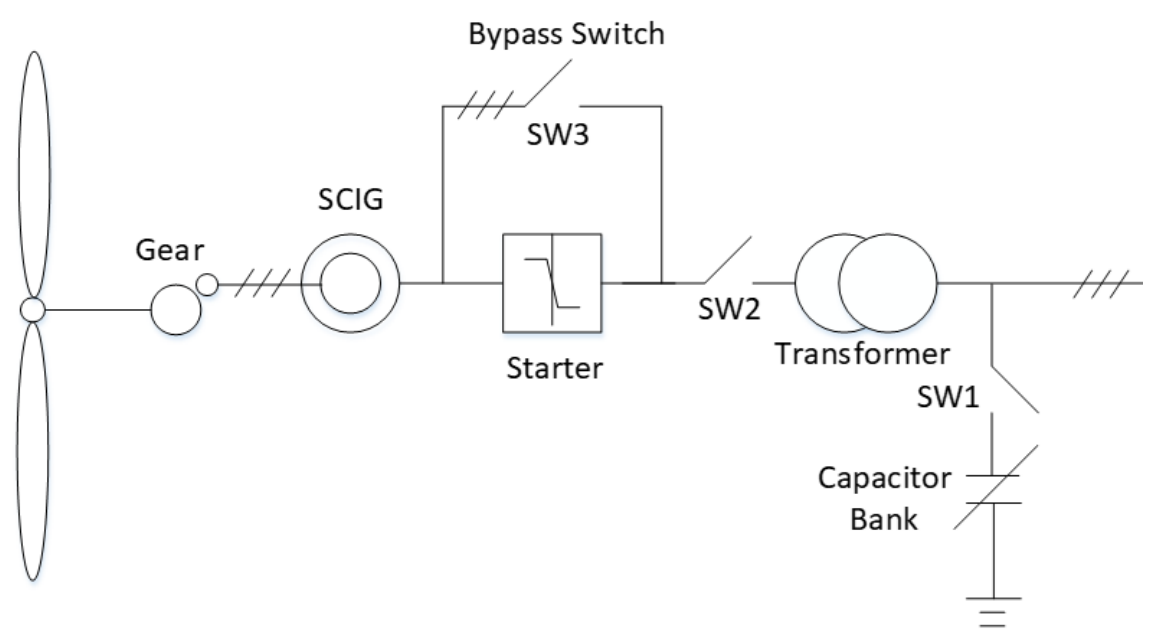

Figure 2 . SCIG based WECS Schematic.

\subsection{Type 3 WECS}

Type 3 WECS is based on the doubly fed induction generator (DFIG). In this study, each DFIG is rated at $1.5 \mathrm{MW}$ and in order to achieve a 9MW capacity windfarm, 6 WECSs are considered operational. Fig. 3 shows the general schematic. Field orientation schemes have been used for both the rotor side controller (RSC) and grid side controller (GSC) with both active and reactive power control achieved through the RSC 
using stator voltage orientation scheme. DC link voltage control, on the other hand, is achieved through the GSC using grid voltage orientation scheme. Parameters of the DFIG are obtained from [22].

\section{Hosted file}

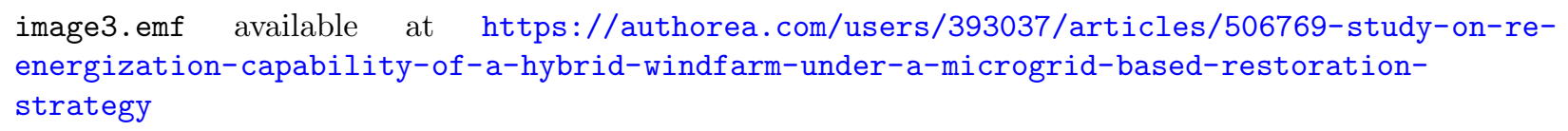

Figure 3 . DFIG based WECS Schematic.

\subsection{Synchronous Condenser}

An 8 MVA synchronous condenser (SC) has been used to provide a voltage reference for stable operation of the windfarm. It also has an added advantage of increasing system inertia, short circuit current, short term overload and low voltage ride through (LVRT) capabilities. In terms of modelling, the SC model is simply a synchronous machine with no mechanical input and a static excitation system [23]. Excitation limiters have also been included in the excitation system to obtain a near accurate response. Excitation limiters included and modelled are overexcitation limiter (OEL) [24], volt/hertz limiter $(\mathrm{V} / \mathrm{Hz})[24]$ and underexcitation limiter (UEL) [25].

\subsection{Dump Load}

A dump load has been used to absorb the excess energy produced by the windfarm. A model similar to [26] has been used in this study. 8 three phase resistors, in series and controlled by ideal GTO switches, are varied in steps of $17.5 \mathrm{KW}$ from 0 to $4.4625 \mathrm{MW}$ in steps of $17.5 \mathrm{KW}$. They are connected in series and controlled by ideal GTO switches. System frequency has been used as the input to control the switches that in turn control the resistor banks.

\subsection{Transformer}

Different sizes of the $33 / 132 \mathrm{kV}$ collector point step-up transformer have been considered in the study to investigate the transformer energization capabilities of the hybrid windfarm. Fig. 4 shows the high frequency model of up to $100 \mathrm{kHz}$ proposed by [27] suitable for transformer energization studies. Description and derivation of the parameters have been discussed in detail in [28]. The model includes saturation effect with hysteresis, short circuit impedance incorporating skin effect, eddy current losses and coupling capacitances.

\section{Hosted file}

image4.emf available at https://authorea.com/users/393037/articles/506769-study-on-reenergization-capability-of-a-hybrid-windfarm-under-a-microgrid-based-restorationstrategy

Figure 4. Single phase Transformer Equivalent Circuit.

\subsection{Transmission Line}

Different lengths of overhead lines and cables have been used to investigate the impact of transmission line (overhead lines and underground cables) energization. In terms of overhead lines, the lengths that have been undertaken are 50,100,150 and 200km lines. For underground cables, the lengths that have been undertaken are 10, 20, 30 and $40 \mathrm{~km}$. Fig. 5 shows the $132 \mathrm{kV}$ transmission line parameters used in this study. 

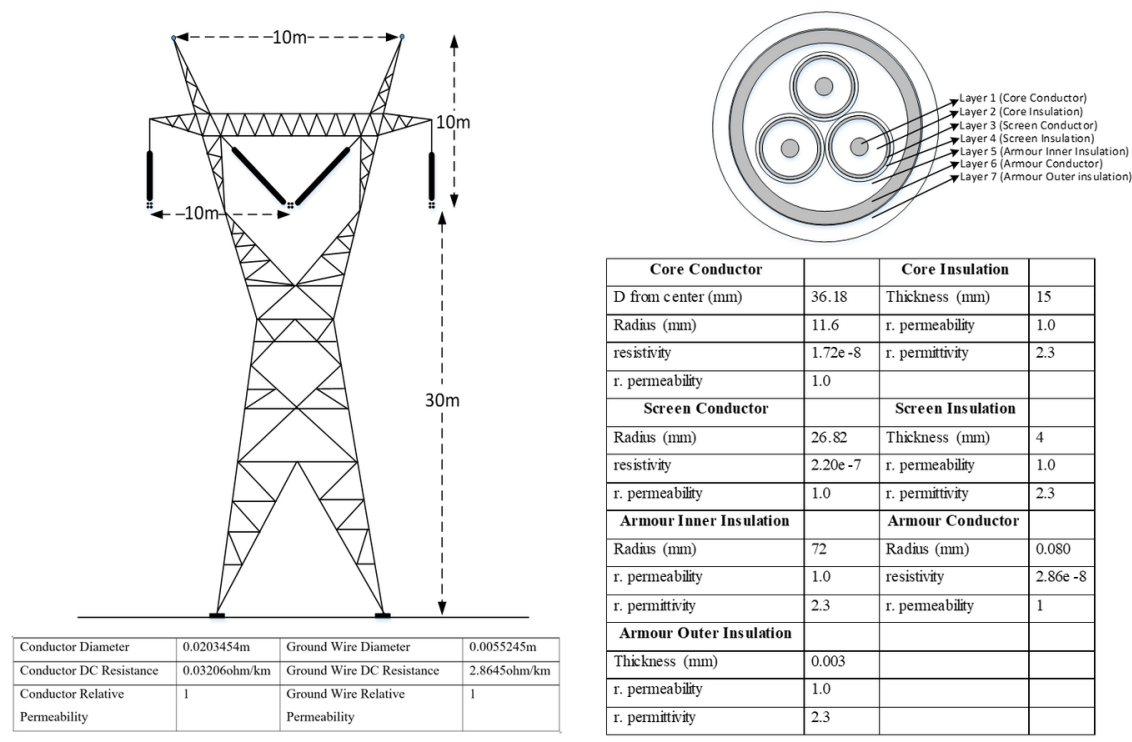

Figure 5. Overhead line and Underground cable parameters.

For simplicity and without much loss in accuracy, multiple PI sections model have been used have been to represent both transmission lines and cables. Derivation of the underground cable PI section has been done as [29]. As a rule of thumb, each individual PI section should not be longer than (1) [27].

$$
L_{\max }=\frac{v}{5 \times f_{\max }}
$$

Where fmax represents the maximum frequency under study, $l$ represents the length of the cable and $v$ represents the cable velocity.

\subsection{Motors}

Motor energization is an important consideration associated with either cranking of thermal based generation or cold load pick up to show the effects of inrush currents which are about 6 times the full load rated current. A 4th order induction motor model [30] has been used to represent the motors.

3. Results and discussion

All across the study, voltage and frequency measurements are taken at the onshore substation at $33 \mathrm{kV}$ level. Field current and excitation limiter outputs measurements are related to the SC. Also Type 1 WECSs will be referred to as SCIG based WECSs while Type 3 WECSs will be referred to as DFIG based WECSs.

\subsection{Range of Operation}

Pickup and drop-off of pure resistive and inductive load was undertaken to determine the normal operating range of the windfarm. This was done to define the limitations on the hybrid windfarm under different scenarios.

\subsubsection{Active Power}

The initial connected load was taken as 4MW. At the 40th second, $3.5 \mathrm{MW}$ of load was dropped, followed by a gradual increase in windspeed from $7 \mathrm{~m} / \mathrm{s}$ to $9 \mathrm{~m} / \mathrm{s}$ at the 60 th second. The aim of this was to investigate the worst-case scenario if there is excess generation at low loading. At the 75 th second, $1.5 \mathrm{MW}$ of load is picked up followed by generation decrease caused by wind gradually decreasing from $9 \mathrm{~m} / \mathrm{s}$ to $7 \mathrm{~m} / \mathrm{s}$, starting 
from the 90th second. The aim of this was to investigate the response on impact of sequential load increase and reduction in generation. Fig. 6 shows the response.
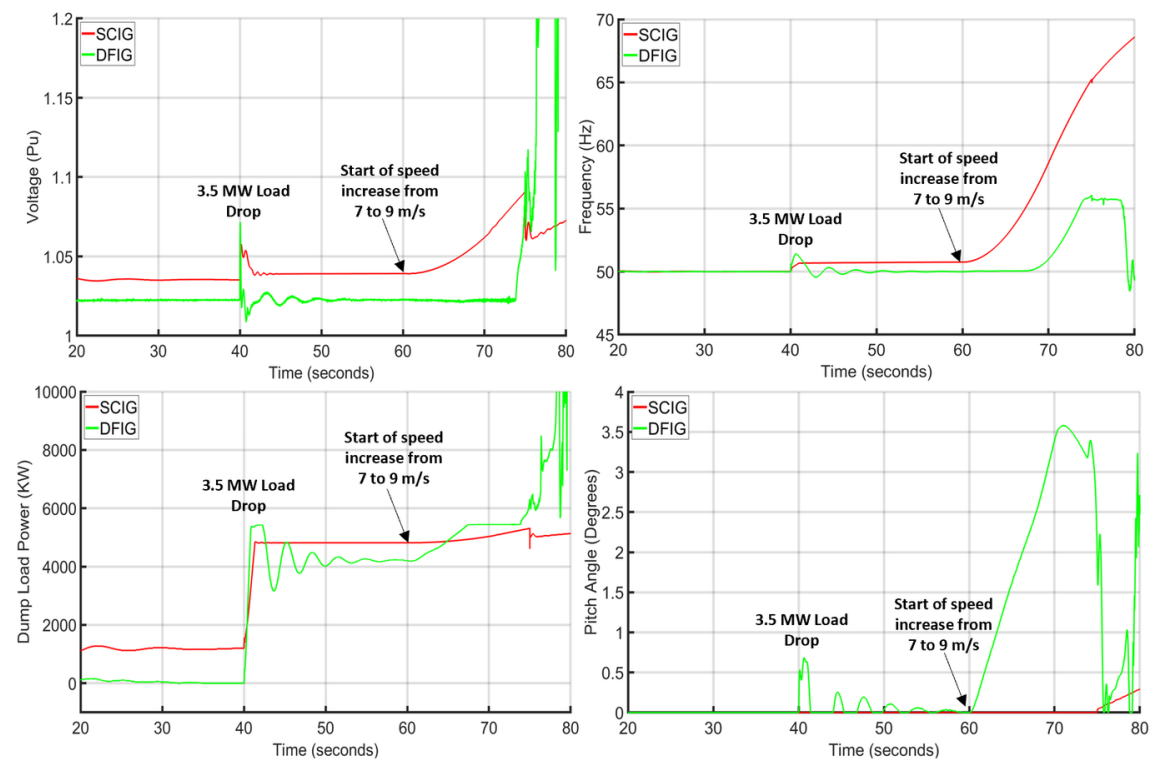

Figure 6 . Response of both SCIG and DFIG based WECSs on the described scenario.

It can be seen that at excess generation conditions and maximum dump load absorption capacity, the system would collapse on overfrequency for the SCIG based system and overvoltage for the DFIG based system. The DFIG based system tried to regulate its power output through the pitch control system but it was not enough to avoid the overfrequency which happened at a later stage as compared to the SCIG based system. The simulation was discontinued at the 80th second due to the collapse thus other events are not shown. An additional simple pitch regulation scheme dependent on the dump load power is proposed. It is implemented using a PI controller obtaining its input from dump load power and if it reaches $80 \%$ of its capacity, the pitch angle is increased to de-load the WECS. Fig. 7 shows the improved network response.
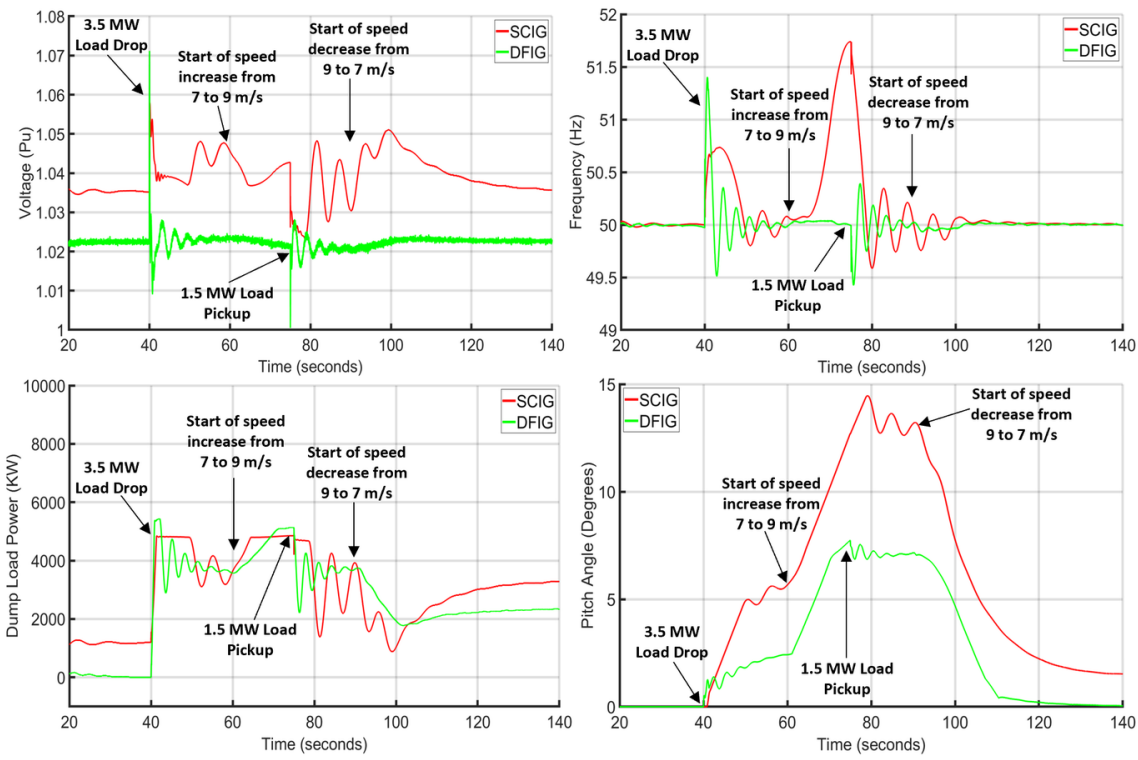
Figure 7. Response of both SCIG and DFIG based WECSs on the described scenario.

It is seen that there is significant improvement in the voltage and frequency response thus coordination is required between the dump load and the WECSs. The DFIG based system performed better in its frequency response due to presence of MPPT that prevents short term variability affecting its operation. The response from the SCIG based system is slow and the additional pitch regulation is not enough during the described scenario thus depending on the overfrequency protection settings, the hybrid windfarm operation would collapse. The dump load power is kept within its limits as compared to the previous scenario. The pitch angle increased as compared to the previous scenario to de-load the WECS in trying to keep the frequency within acceptable limits.

\subsubsection{Reactive Power}

A similar exercise as above was conducted to assess the response of the network on pick up of theoretically near-pure inductive load (for example unloaded transformer and motor). In the case of SCIG based system, the reactive power source in the system is the $\mathrm{SC}$ and available reactive compensation in the form of capacitor banks while for the DFIG based system, the reactive power source is still the SC and DFIG itself which has an reactive power operational range of $\pm 30 \%$ of its rated capacity. The system capability to pick up reactive load, considering both SCIG and DFIG based systems, is dependent on the network's level of excitation at the time of load pickup. Fig. 8 shows the response on the SCIG based system on pickup of different sizes of inductive load at different levels of excitation.
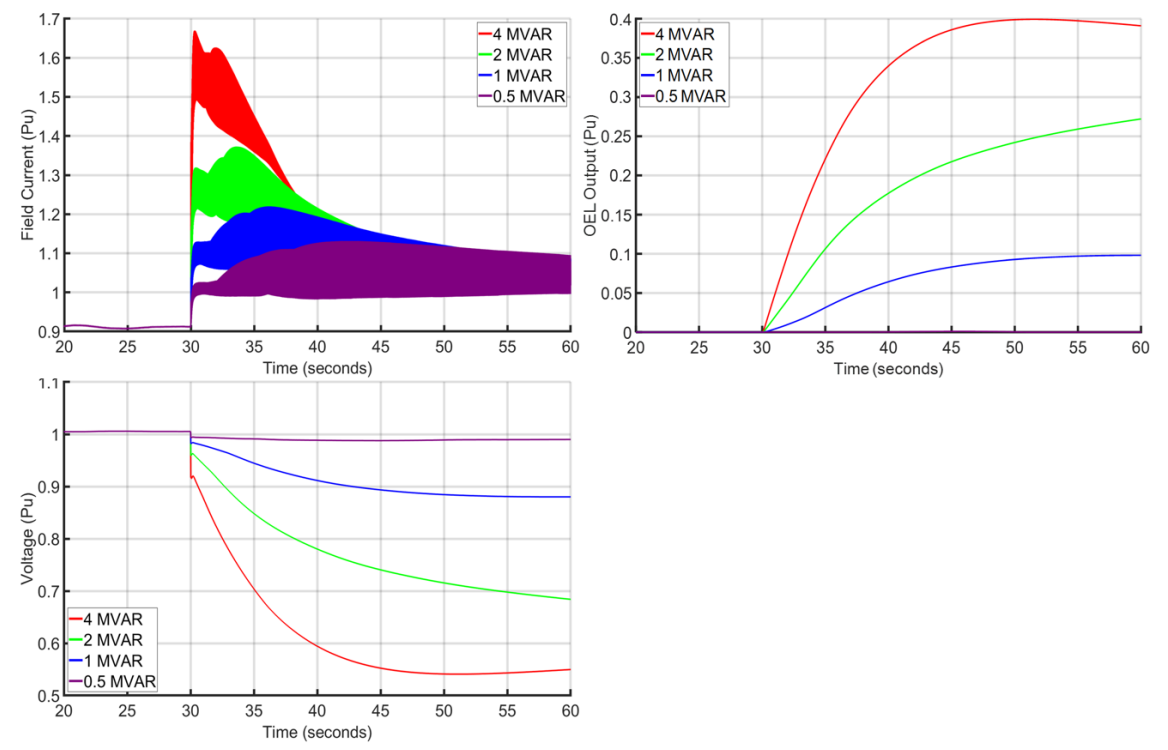

Figure 8. SCIG based system response on pure inductive load pickup with $90 \%$ level of excitation.

There is significant rise in the field current as expected and above the 1.05pu OEL activation limit for inductive loads of 1MVAR and above. This prompts the OEL to reduce the AVR reference voltage in turn reducing the terminal voltage of the $\mathrm{SC}$ and in turn of the system. The allowable steady state minimum voltage is $0.9 \mathrm{pu}$ which is when the ride through strategies that are meant for short term voltage sags are activated. The level of excitation can be lowered to $50 \%$ by adjusting the SC AVR or by energization of more capacitor banks. Although lowering of the AVR reference would lead to lowering of the excitation level, the system voltage would also decrease, and this is not desirable. It is thus preferred to energize a capacitor bank as it would lower the excitation level and at the same time increase the voltage. In this case, a 1.4 MVAr capacitor bank was energized (not shown but energized at $10^{\text {th }}$ second). This drove the SC to operate in underexcitation mode, so as to pick up more reactive load. Fig. 9 show the results obtained: 

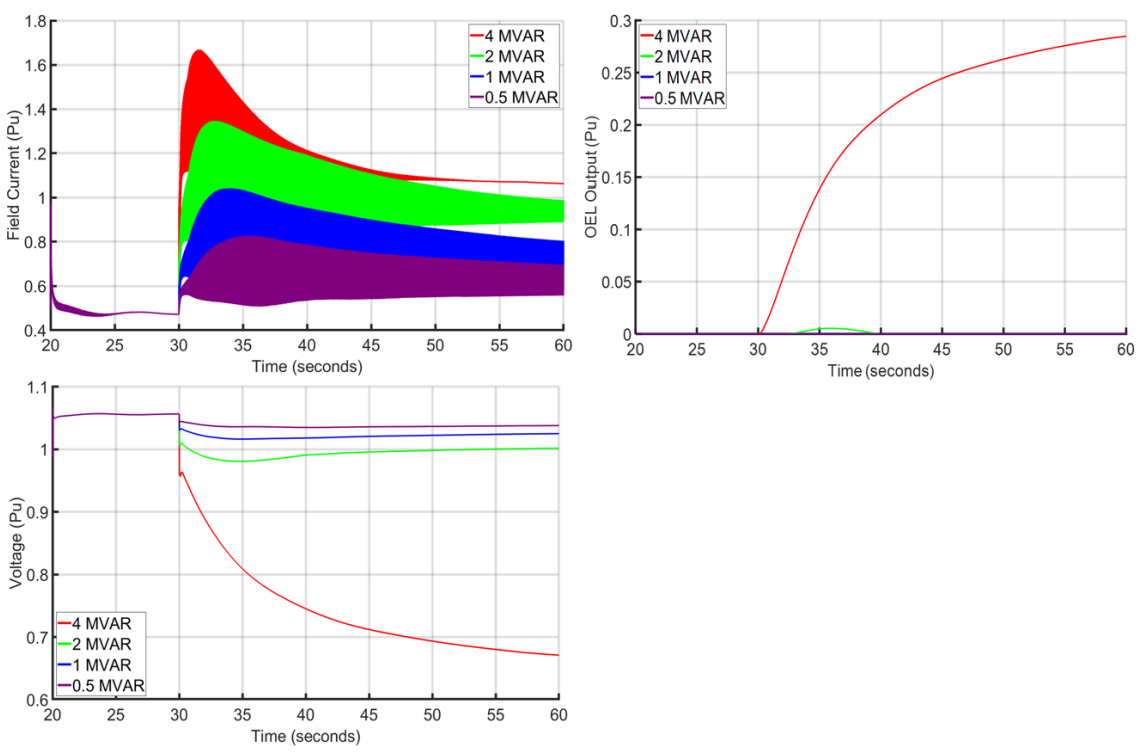

Figure 9. SCIG based system response on pure reactive load pickup with $90 \%$ level of excitation.

Significant improvements are observed and now 2 and 1MVAr inductive loads can be picked up with the SC in underexcited mode. The OEL acted swiftly on picking up of the 4MVAr load. This led to significant drop in voltage which would lead to system collapse. The action on the pickup of the 2MVAr load was minor and the voltage still remained within acceptable technical limit. It is thus recommended for the system to have 2MVAr as the limit for the SCIG based hybrid system.

A similar exercise is conducted for the DFIG based hybrid system. Fig. 10 shows the results obtained at $100 \%$ excitation level. As observed, the pickup of even the smallest inductive load block prompted the OEL to reduce the voltage but not to low levels as compared to the SCIG based system. This is due to rotor control with the q component of rotor current re-adjusting to maintain the voltage to within acceptable limits. Also, the inductive load is picked up by both the DFIG and SC. On lowering the level of excitation to $50 \%$, by adjusting the DFIG reference reactive power so as to drive the SC in underexcitation mode, Fig. 11 shows the results obtained. Significant improvements are observed and now for 2, 1 and 0.5MVAr blocks, the voltages do not drop below 1pu. The OEL still acted significantly on picking up of the 4MVAr load. It is thus recommended for the system to have 2MVAr, similar to SCIG based system, as the limit for the DFIG based system. 

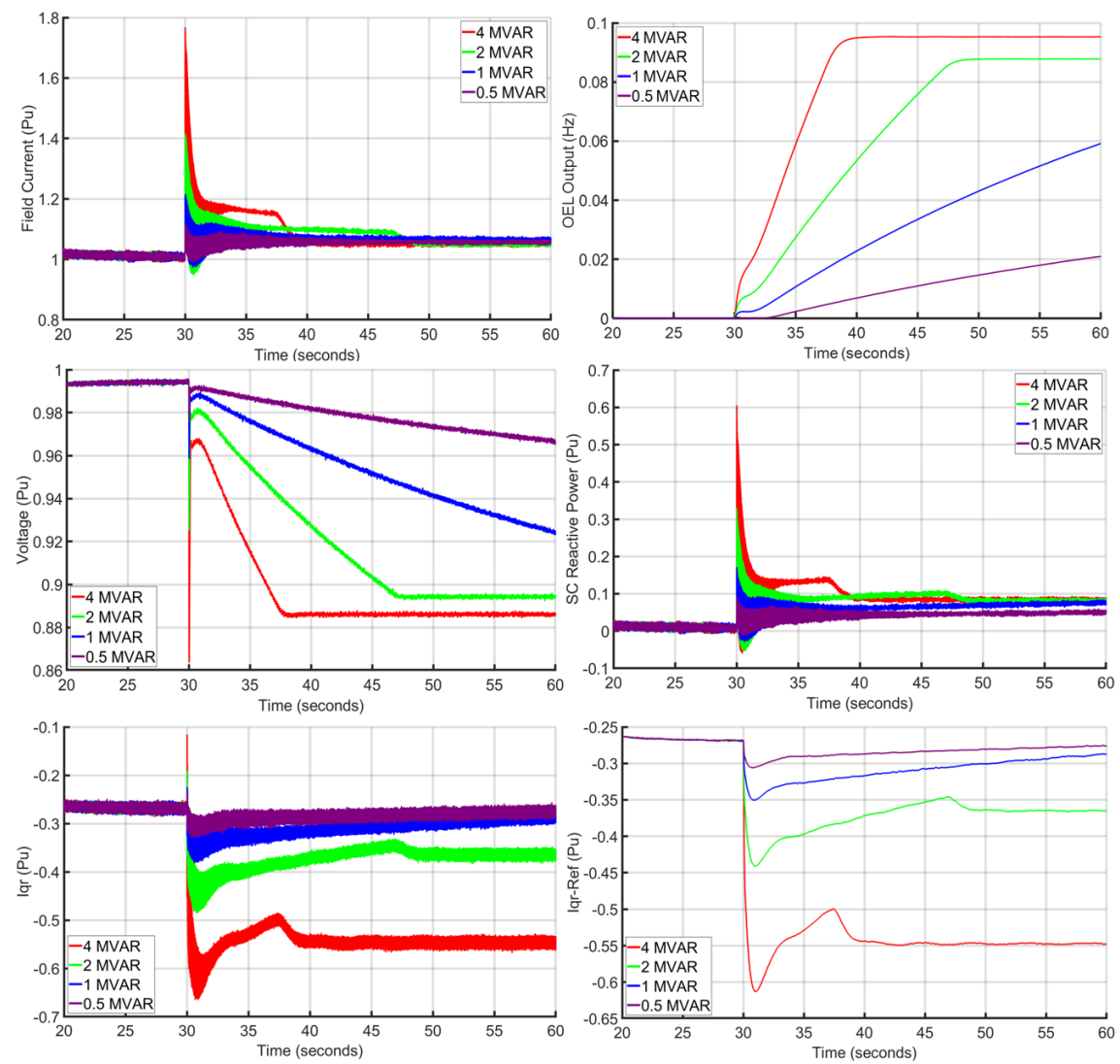

Figure 10. DFIG based system response on pure reactive load pickup at $100 \%$ level of excitation. 

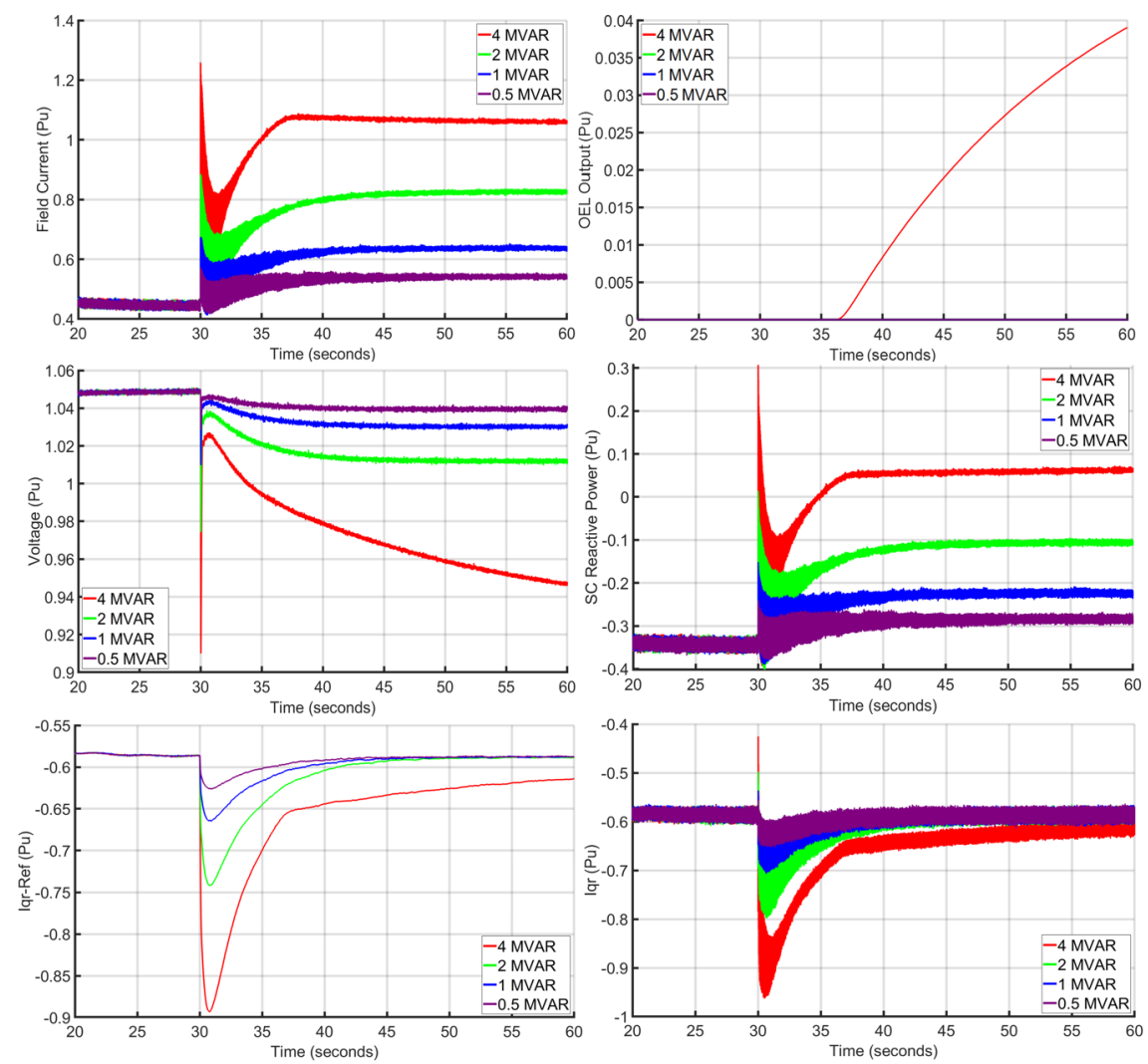

Figure 11. DFIG based system response on pure reactive load pickup at $50 \%$ level of excitation.

\subsubsection{Power Quality Assessment}

The 2 common issues related to power quality are flicker and harmonics. Flicker is defined as 'an impression of unsteadiness of visual sensation induced by a light stimulus whose luminance or spectral distribution fluctuates with time' [31]. Harmonics, on the other hand, is defined as 'sinusoidal voltages or currents having frequencies that are integer multiple of the frequency at which the supply system is designed to operate' [31].

Flicker assessment methodology has been described in IEC 61000-4-15 [32]. Two common metrics are used: Short term flicker taken over a maximum 10-minute period and long-term flicker taken as a cubic mean of the short-term flicker values over a 2-hour period. These metrics are normalized to between 0 and 1 where 1 means 'voltage fluctuations sufficient to cause noticeable flicker to 50\% of a sample observing group' [32]. Flicker was investigated by assuming a $\pm 2 \mathrm{~m} / \mathrm{s}$ wind speed range within a period of 5 seconds. Fig. 12 shows the network response. 

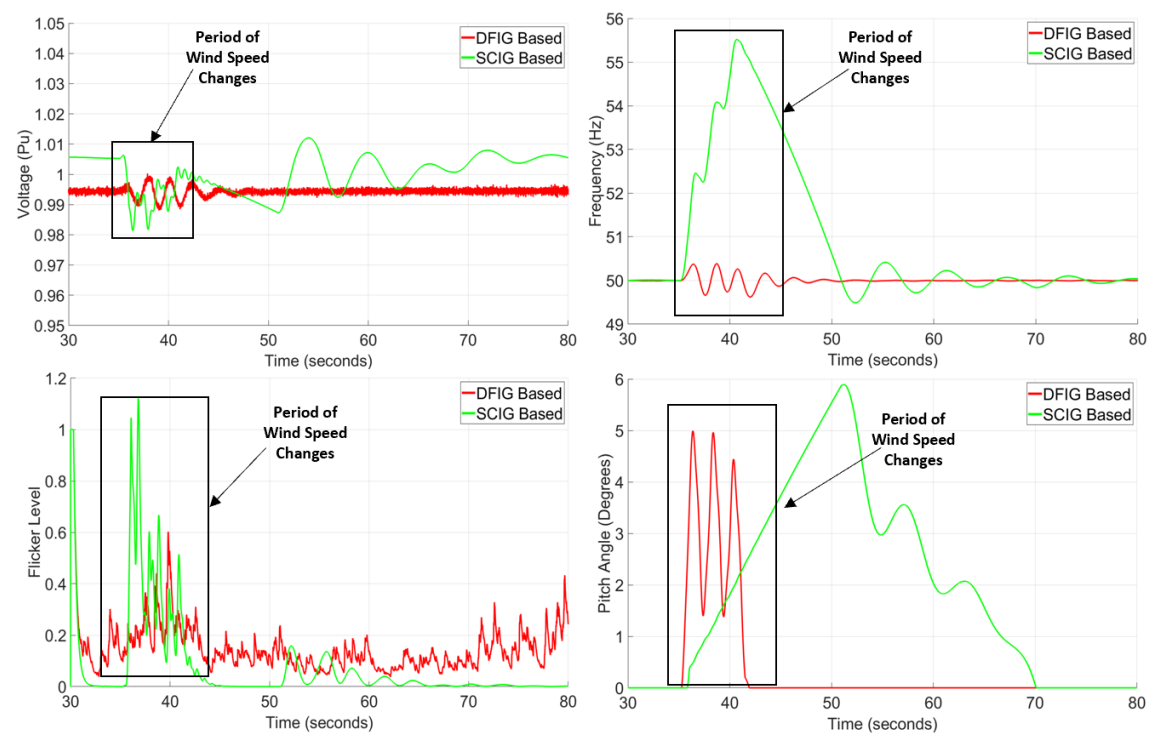

Figure 12. Response of SCIG and DFIG based system to rapid wind speed changes.

From the voltage and frequency observations, it is observed that the DFIG based system responded better to rapid wind fluctuations compared to the SCIG based system of which its frequency goes above the acceptable technical limit of $50.5 \mathrm{~Hz}$. The pitch regulation of the SCIG is much slower as compared to the DFIG based system. The DFIG has an additional control system in form of the MPPT that enables it to track and optimize the available windspeed with the turbine characteristics, thus aiding in pitch control. With regards to the flicker measurement, the SCIG based system operated beyond the acceptable technical limit of 1 while the DFIG remained below 1 during the 5-second period. Although this study does not cover flicker mitigation, an active voltage controller, for example a STATCOM, is required to counter the flicker especially for the SCIG based system.

Harmonic assessment and acceptable harmonic limits have been formalised by IEEE standard 519 [33]. The measurement window is recommended to be over a 10 cycle period. The technical limits for a voltage signal at $33 \mathrm{kV}$ are $5 \%$ for THD and $3 \%$ for any single harmonic. Table 1 below shows the THD for both SCIG and DFIG based systems for a period of 4 seconds.

Table 1. THD for both SCIG and DFIG based Hybrid System.

\begin{tabular}{llllll}
\hline Scenario Time & 4 SCIGs SC-8MVA & 5 SCIGs SC-8MVA & 6 SCIGs SC-10MVA & 6 DFIGs SC-8MVA & 7 D \\
\hline $\mathbf{3 0 . 0}$ & 0.09 & 0.20 & 0.54 & 1.20 & 1.2 \\
$\mathbf{3 0 . 2}$ & 0.14 & 0.25 & 0.47 & 1.11 & 1.30 \\
$\mathbf{3 0 . 4}$ & 0.19 & 0.29 & 0.37 & 1.11 & 1.10 \\
$\mathbf{3 0 . 6}$ & 0.23 & 0.33 & 1.09 & 1.2 \\
$\mathbf{3 0 . 8}$ & 0.26 & 0.35 & 0.20 & 1.06 & 1.20 \\
$\mathbf{3 1 . 0}$ & 0.29 & 0.38 & 0.11 & 1.12 & 1.10 \\
$\mathbf{3 1 . 2}$ & 0.32 & 0.38 & 0.03 & 1.20 & 1.12 \\
$\mathbf{3 1 . 4}$ & 0.32 & 0.38 & 0.15 & 1.17 & 1.1 \\
$\mathbf{3 1 . 6}$ & 0.32 & 0.37 & 0.24 & 1.17 & 1.07 \\
$\mathbf{3 1 . 8}$ & 0.31 & 0.35 & 0.30 & 1.02 & 1.2 \\
$\mathbf{3 2 . 0}$ & 0.30 & 0.32 & 0.37 & 1.04 &
\end{tabular}




\begin{tabular}{llllll}
\hline Scenario Time & 4 SCIGs SC-8MVA & 5 SCIGs SC-8MVA & 6 SCIGs SC-10MVA & 6 DFIGs SC-8MVA & 7 D \\
\hline $\mathbf{3 2 . 6}$ & 0.23 & 0.22 & 0.46 & 1.08 & 1.3 \\
$\mathbf{3 2 . 8}$ & 0.20 & 0.18 & 0.49 & 1.17 & 1.21 \\
$\mathbf{3 3 . 0}$ & 0.17 & 0.14 & 0.51 & 1.19 & 1.1 \\
$\mathbf{3 3 . 2}$ & 0.14 & 0.10 & 0.52 & 1.14 & 1.10 \\
$\mathbf{3 3 . 4}$ & 0.11 & 0.06 & 0.49 & 1.11 & 1.1 \\
$\mathbf{3 3 . 6}$ & 0.09 & 0.02 & 0.46 & 1.17 & 1.20 \\
$\mathbf{3 3 . 8}$ & 0.07 & 0.02 & 0.3500 & 1.1240 & 1.20 \\
Average & 0.2165 & 0.2445 & & & \\
\hline
\end{tabular}

As expected, the DFIG contribution is higher, but still within the technical limits, as compared to SCIG due to the inverter interface at the rotor side. With connection of more DFIGs, the THD will also increase unless a higher capacity SC is connected to the network.

Flicker (for the SCIG based system) and Harmonic assessment (for the DFIG based system) can both be used in determining the hosting capacity of the hybrid system.

\subsection{Cranking up of other WECS}

A study is undertaken to determine the effect of starting other WECSs in the same string as the already operational WECSs. Modelling of the DFIG starting procedure has been discussed in previous research by the same author [34]. SCIG based WECS applies the same torque control scheme. Figs. 13 and 14 shows the results obtained.
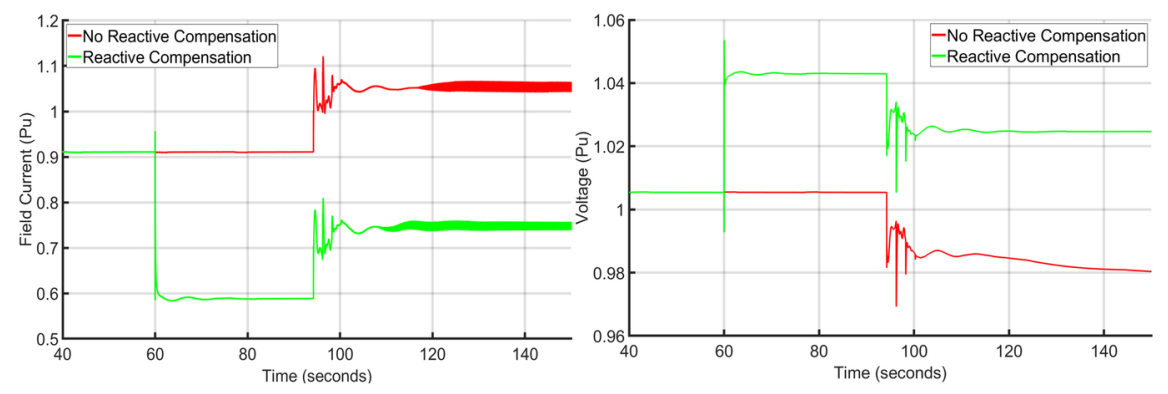

Figure 13. Response on SCIG WECS starting on a SCIG based system.

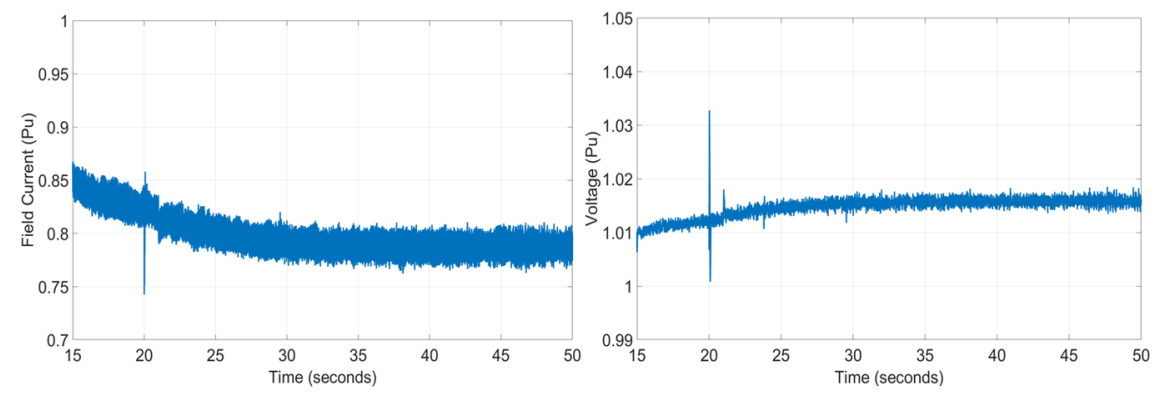

Figure 14. Response on DFIG WECS starting on a DFIG based system.

From the results obtained, starting of SCIG based WECS first requires energization of a capacitor bank (at the 60th second) to supply its reactive power requirements. Without the capacitor bank energization, the $\mathrm{SC}$ as shown by the field current would be driven into overexcitation prompting action of the OEL. For the 
case of the starting of the DFIG based WECS, there is a sluggish response, but the SC is not driven into overexcitation and in contrast it behaves as a capacitive element reducing the operating level of SC field current.

\subsection{Transformer Energization}

Figs. 15 to 18 show the system response on transformer energization at different excitation levels for both the SCIG and DFIG based hybrid systems. Change of excitation level for the SCIG system is achieved by energizing a 0.5MVAr capacitor bank while for the DFIG based system it is achieved by setting the Q reference to $0.1 \mathrm{pu}$ on each WECS.
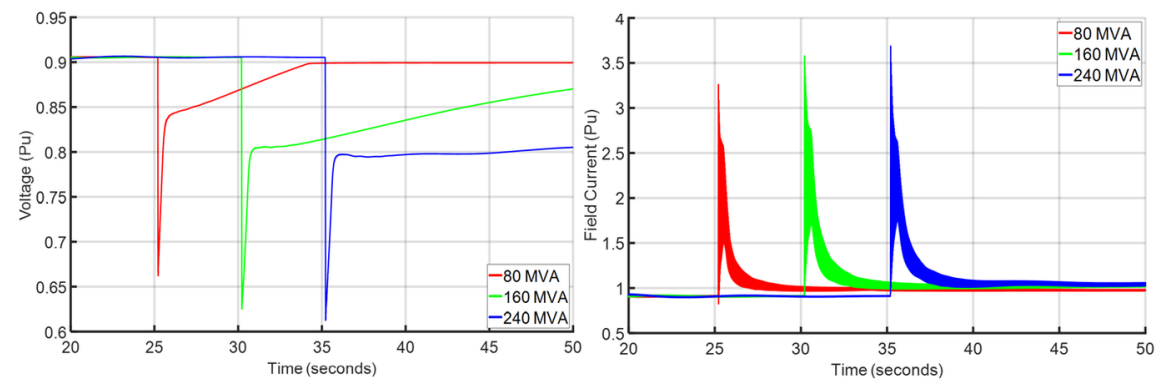

Figure 15. Response on transformer energization at $100 \%$ excitation level in a SCIG based hybrid system.
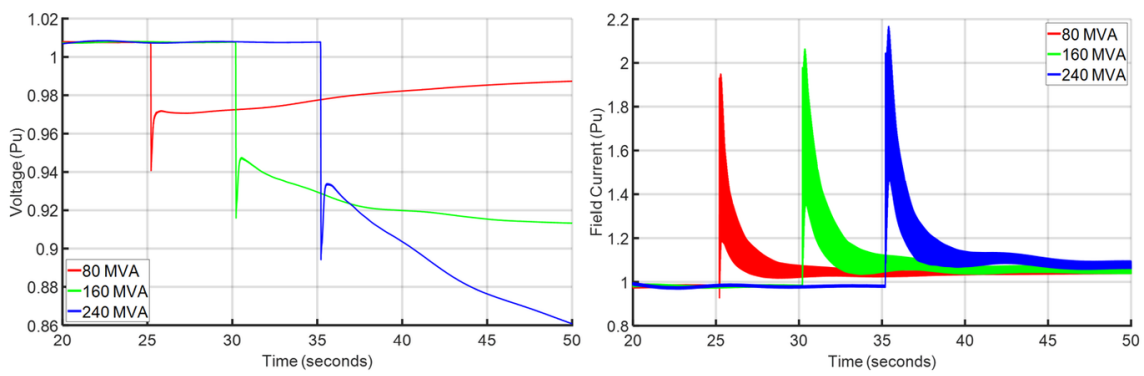

Figure 16. Response on transformer energization at $90 \%$ excitation level in a SCIG based hybrid system.
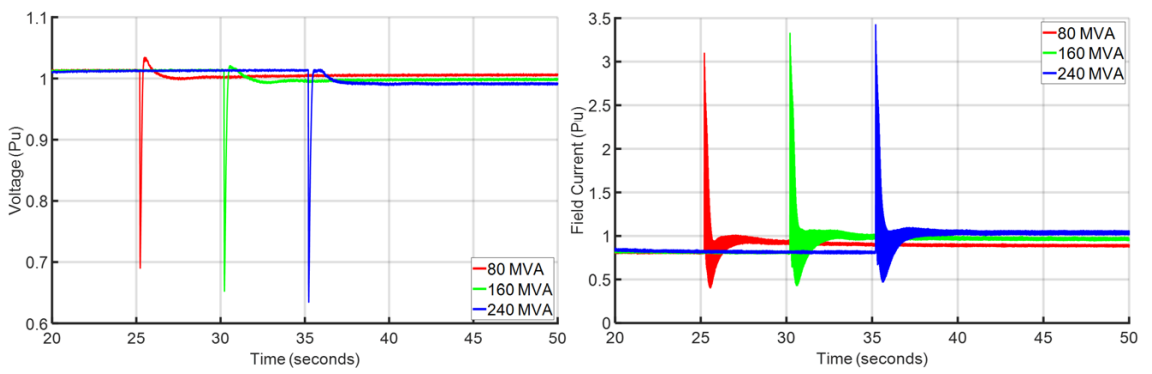

Figure 17. Response on transformer energization at 100\% excitation level in a DFIG based hybrid system. 

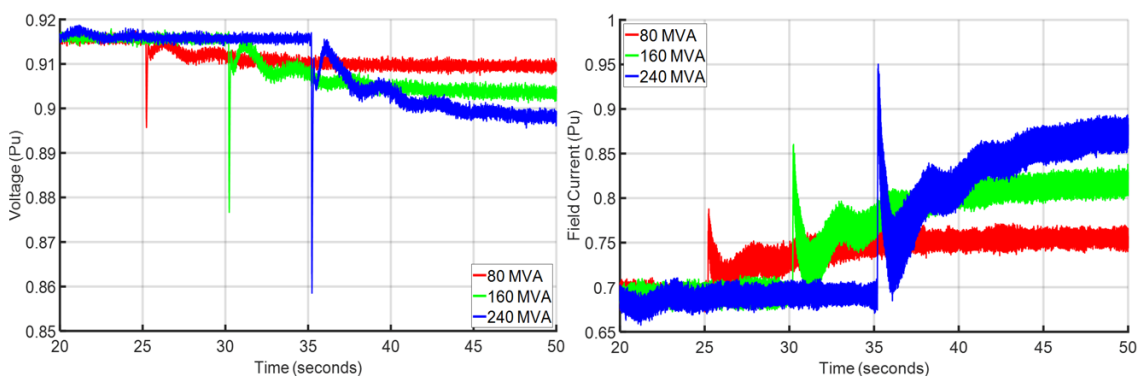

Figure 18. Response on transformer energization at 70\% excitation level in a DFIG based hybrid system.

From the responses above, energization at $100 \%$ excitation levels led to the SC field current being above an acceptable technical limit of 2.2pu [35]. This was the case for energization of the all the selected transformer sizes for both SCIG and DFIG based hybrid system. On energization at lower excitation levels (90\% for the SCIG and $70 \%$ for the DFIG) the field current transient is kept below $2.2 \mathrm{pu}$ for energization of the selected transformer sizes. From the voltage response, the windfarm is assumed to sustain the transients considering typical low voltage ride through capabilities [36]. At both excitation levels, the voltage response from the DFIG system is better, although slower, in comparison to the SCIG based system. The SCIG based system could handle the energization better if the excitation is lowered further while keeping the voltage above $1 \mathrm{pu}$. This is achieved by energization of larger capacitor banks.

\subsection{Underground Cable Energization}

Although the cable infrastructure can be assumed energized during energization of the windfarm auxiliaries before starting of the WECSs if the energization source is located onshore, a scenario might emerge in which the initial excitation source is located offshore thus the HV submarine cable to the onshore substation requires energization. Response on energization of a $40 \mathrm{~km}$ cable at $80 \%$ and $100 \%$ compensation levels is shown in Figs. 19 and 20.
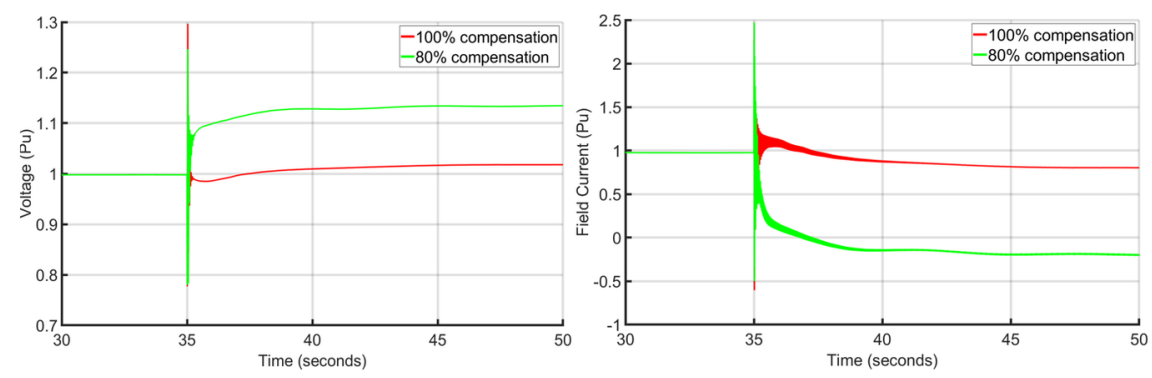

Figure 19. Response on HV cable energization for a SCIG based hybrid system.
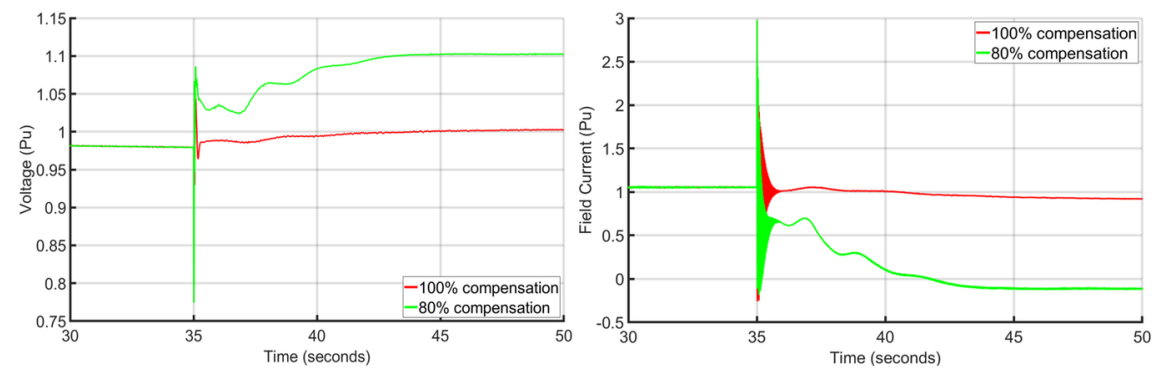
Figure 20. Response on HV cable energization for a DFIG based hybrid system.

From above, it is possible to energize a $\mathrm{HV}$ cable if there is proper compensation. In this case there is sufficient capability from the SC and for $80 \%$ compensation, it is driven to underexcitation and negative excitation. Negative forcing excitation capability is possible in static excitation systems if excess short-term reactive power absorption capabilities are required. However, this prompted the UEL to increase the AVR voltage reference thus the increase in the RMS voltage to $1.1 \mathrm{pu}$ for the DFIG and 1.15pu for the SCIG which is the higher limit of the range of voltage at MV level. One of the major challenges associated with simultaneous energization of compensated transmission lines is the missing zero phenomenon. This occurs when the current through a breaker does not cross the zero mark for a few cycles. This is dangerous if there is a fault that needs to be cleared during the few cycles leading to circuit breaker (CB) damage when trying to open. In investigating the missing zero phenomenon on the compensated lines, Figs. 21 and 22 show the stator current response on cable energization at different compensation levels.
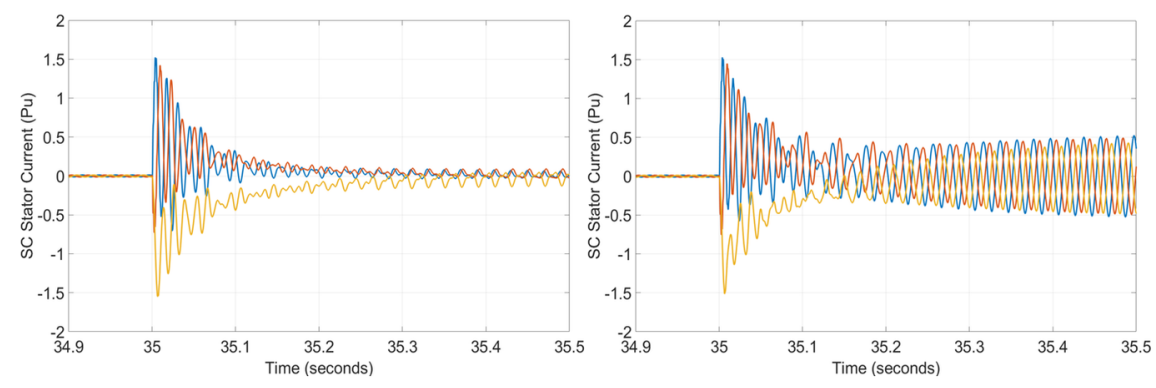

Figure 21. SC Stator Current on HV cable energization (100\% compensation, $80 \%$ compensation) in a SCIG based hybrid system.
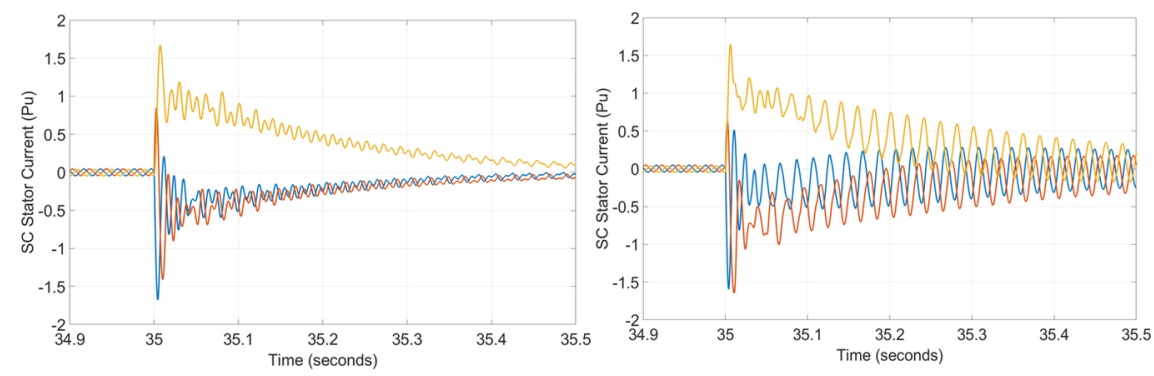

Figure 22. SC Stator Current on HV cable energization (100\% compensated, $80 \%$ compensation) in a DFIG based hybrid system.

At the recommended 100\% compensation level (from the voltage response of Figs. 21 and 22), there is an increased chance of missing zero phenomenon which is more pronounced on the DFIG based system as compared to the SCIG based system. The more capacitive the system at the time of energization the less the missing zero phenomenon effect. For the SCIG based system, there are connected capacitor banks (required for normal operation) which makes the system net capacitive as compared to DFIG based system that does not require external capacitive elements as it does its reactive power management internally through the RSC or GSC.

\subsection{Overhead Line Energization}

Assuming that there is a non-blackstart unit located more than $50 \mathrm{~km}$ away from the windfarm, the $132 \mathrm{kV}$ overhead lines between the windfarm and the non-blackstart unit will need to be energized. Figs. 23 and 
24 show results obtained on overhead line energization by both a SCIG and DFIG based hybrid system. Energization of $100 \mathrm{~km}$ and $200 \mathrm{~km}$ lines required some form of compensation: 0.6 and $0.8 \mathrm{MVAr}$ respectively.
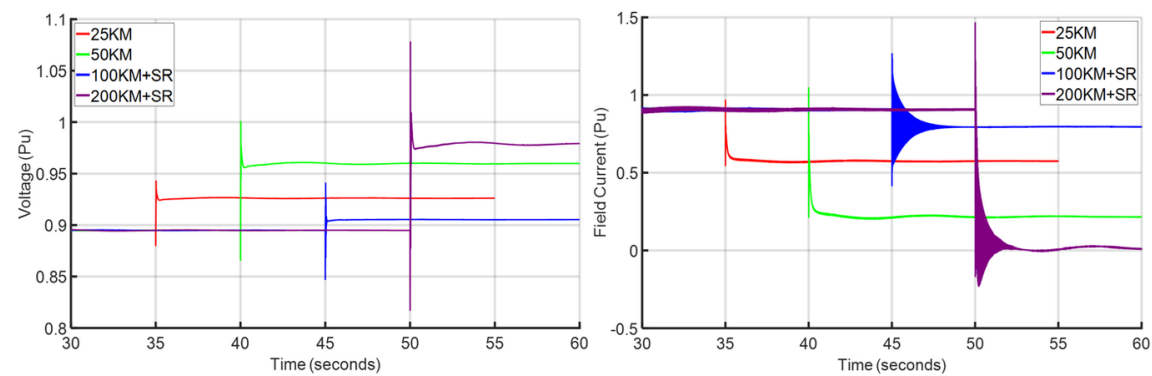

Figure 23. Response on Overhead Line energization for a SCIG based hybrid system.
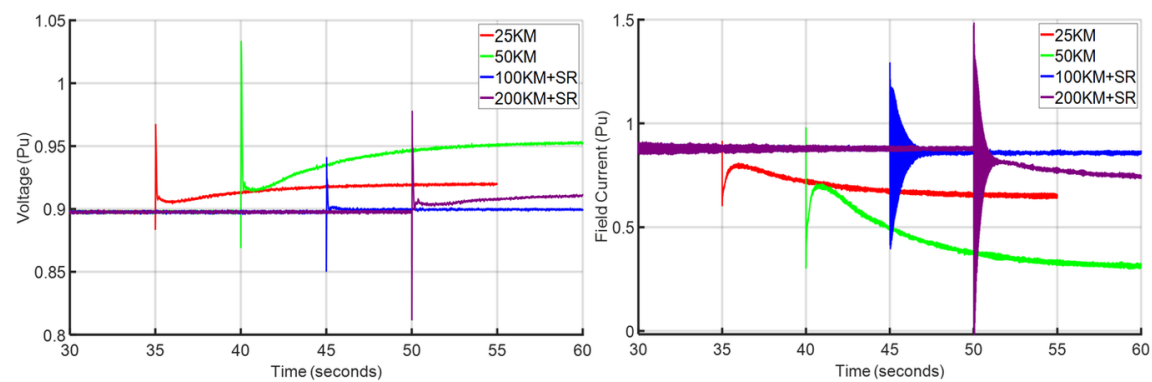

Figure 24. Response on Overhead Line energization for a DFIG based hybrid system.

From above, it was possible to energize at least $50 \mathrm{~km}$ of overhead line without any form of compensation. Some form of compensation was required for lines above this and this is seen in the energization of the $100 \mathrm{~km}$ and $200 \mathrm{~km}$ lines. Since the lines were being energized at $0.9 \mathrm{pu}$, the rise in voltage was not significant as compared to cable energization earlier mentioned. On investigating the missing zero phenomenon on the SC stator current, Fig. 25 shows the results obtained.
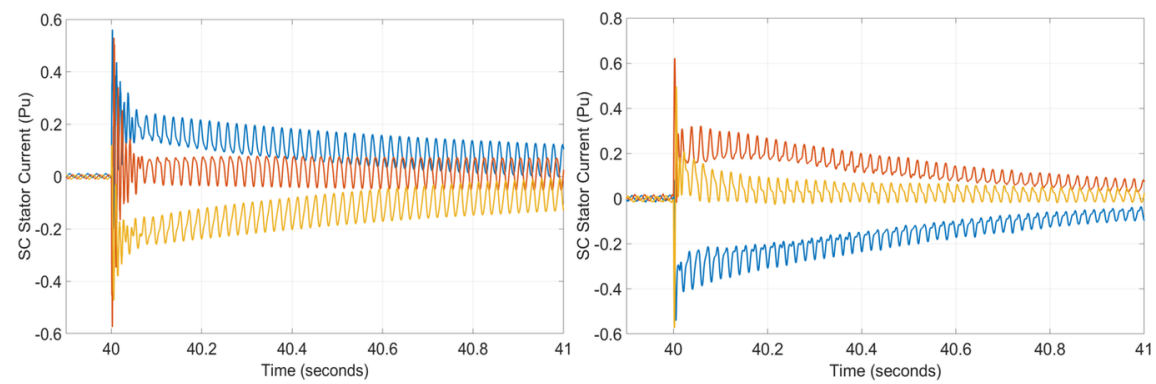

Figure 25. SC Stator Current on 100kM Overhead Line energization for a SCIG (left) and DFIG (right) based hybrid system.

As previously explained, the missing zero phenomenon was more significant for the DFIG based system as compared to the SCIG system as a result of presence of capacitor banks making the system more capacitive for the SCIG based hybrid system.

3.6. Cold Load Pickup-Motor Energization 
Still on the assumption that there is a non-black start unit located $50 \mathrm{~km}$ from the windfarm, and with the knowledge of maximum reactive power pickup of around 2MVAr, a 3MVA motor was assumed to be the largest motor in the plant. Fig. 26 shows the results obtained for both the SCIG and DFIG based system.
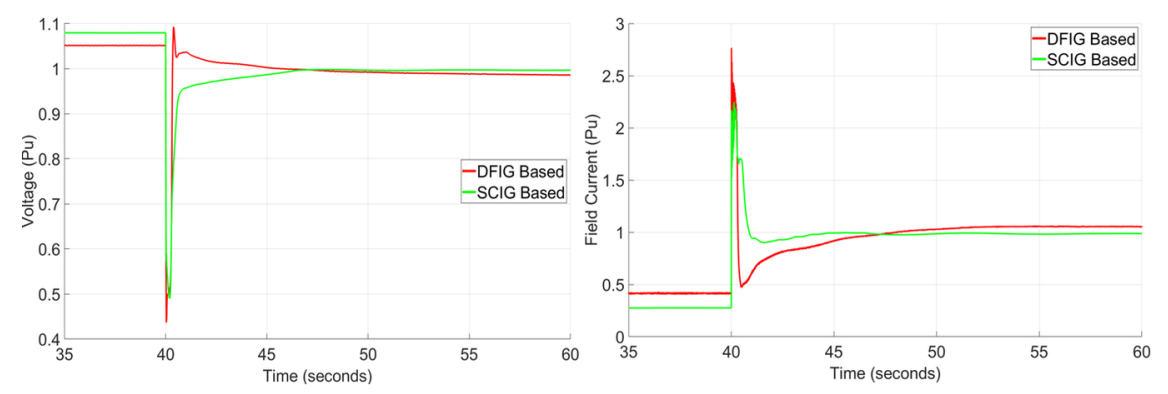

Figure 26. Response on motor energization.

The field current for the DFIG went beyond its limit of $2.2 \mathrm{pu}$ because it was energized at a slightly higher excitation level. With proper setting of the DFIG reactive power reference, it is possible to energize the motor at lower excitation thus keeping the energization transient to below 2.2pu. The voltage dip associated with motor starting last for about a second and this is permissible as per most low voltage ride through criterion.

\section{Conclusion}

Analysis on SCIG and DFIG based hybrid windfarm in emergency restorative conditions with focus on load pickup and component re-energization is provided. The range of operation of both the windfarms was first analyzed from both an active and reactive power response perspective. An additional pitch control based on dump load power was implemented to prevent the excess production of power at a time when the dump load power absorption power has been exceeded. The ability to pick up inductive load for the SCIG based system is governed by the SC capability and availability of capacitor banks while for the DFIG system, it is dependent on the both the SC and DFIG reference settings which can be adjusted to lower the excitation levels and pick up more inductive load.

The 2 most common power quality issues related to windfarm operation, harmonics and flicker, have been used to determine the hosting capacity of the respective hybrid systems. Due to reduced network sources in restorative conditions, harmonic and flicker effect will be more magnified. As expected, flicker has a significant effect on the SCIG based system while harmonics have a significant effect on the DFIG based system. For maximum wind speed variation (worst case scenario) the voltage and frequency of the SCIG based hybrid system could not stay within its technical limit thus flicker mitigation techniques are required. This was not an issue for the DFIG based system. The harmonic levels were well below the limit for the DFIG based hybrid system.

The capability of the hybrid systems to perform re-energization functions, similar to conventional blackstart units was investigated. This has been successfully proven for the case of transformer, HV underground cable, overhead lines and motor energization. Cranking up of other WECSs in the same windfarm was also examined using previous work (by the same author) proposed windfarm starting model. Regulation of the excitation levels is important for proper re-energization. Careful consideration is required for DFIG based hybrid systems on energization of compensated lines due to the increased risk of missing zero phenomenon. Apart from that, the DFIG based hybrid system was superior in performance and flexibility.

Acknowledgments

The authors acknowledge funding support to carry out this research from Ministry of Business, Innovation and Employment, New Zealand's National Science Challenge- Resilience to Nature's Challenge and in par- 
ticular the project on Electricity Distribution Resilience Framework informed by West Coast Alpine Fault Scenario; University of Auckland under Faculty Research Development Fund (FRDF) Grant 3709532 and QuakeCoRE-New Zealand Centre for Earthquake Resilience.

References

[1] H. Yunhe, C. Liu, Z. Pei, and K. Sun, "Constructing power system restoration strategies," in 2009 International Conference on Electrical and Electronics Engineering - ELECO 2009 , 5-8 Nov. 2009 2009, pp. I-8-I-13, doi: 10.1109/ELECO.2009.5355208.

[2] K. Zeng, J. Wen, L. Ma, S. Cheng, E. Lu, and N. Wang, "Fast Cut Back Thermal Power Plant Load Rejection and Black Start Field Test Analysis," Energies, vol. 7, no. 5, 2014, doi: 10.3390/en7052740.

[3] M. M. Adibi, Power System Restoration: Methodologies 83 Implementation Strategies . IEEE Power Engineering Society, 2000.

[4] IRENA, "Towards 100\% Renewable Energy: Status, Trends and Lessons Learned," 2019.

[5] D. K. Maina and N. C. Nair, "Recent advancements on power system restoration," in 2017 IEEE Innovative Smart Grid Technologies - Asia (ISGT-Asia) , 4-7 Dec. 2017 2017, pp. 1-5, doi: 10.1109/ISGTAsia.2017.8378461.

[6] M. Ye, Y. Liu, K. Du, and X. Gu, "Black start scheme formation considering dynamic wind power penetration limit," in 5th IET International Conference on Renewable Power Generation (RPG) 2016 , 21-23 Sept. 2016 2016, pp. 1-6, doi: 10.1049/cp.2016.0540.

[7] H. Zhu and Y. Liu, "Aspects of power system restoration considering wind farms," in International Conference on Sustainable Power Generation and Supply (SUPERGEN 2012) , 8-9 Sept. 2012 2012, pp. 1-5, doi: $10.1049 / \mathrm{cp} .2012 .1788$.

[8] H. Rui, H. Weihao, L. Pengfei, S. Chi, and Z. Chen, "A Dynamic Programming based method for optimizing power system restoration with high wind power penetration," in 2016 IEEE 8th International Power Electronics and Motion Control Conference (IPEMC-ECCE Asia) , 22-26 May 2016 2016, pp. 20222027, doi: 10.1109/IPEMC.2016.7512606.

[9] A. M. El-Zonkoly, "Renewable energy sources for complete optimal power system black-start restoration," IET Generation, Transmission \& Distribution, vol. 9, no. 6, pp. 531-539, 2015, doi: 10.1049/ietgtd.2014.0646.

[10] L. Seca, H. Costa, C. L. Moreira, and J. A. P. Lopes, "An innovative strategy for power system restoration using utility scale wind parks," in 2013 IREP Symposium Bulk Power System Dynamics and Control - IX Optimization, Security and Control of the Emerging Power Grid , 25-30 Aug. 2013 2013, pp. 1-8, doi: 10.1109/IREP.2013.6629404.

[11] S. K. Chaudhary, R. Teodorescu, and P. Rodriguez, "Wind Farm Grid Integration Using VSC Based HVDC Transmission - An Overview," in2008 IEEE Energy 2030 Conference , 17-18 Nov. 2008 2008, pp. 1-7, doi: 10.1109/ENERGY.2008.4781061.

[12] T. Wei, W. Hongtao, and J. Yingzhe, "Construction and control strategy research of black start unit containing wind farm," in TENCON 2015 - 2015 IEEE Region 10 Conference , 1-4 Nov. 2015 2015, pp. 1-5, doi: 10.1109/TENCON.2015.7372862.

[13] Y. Tang, J. Dai, Q. Wang, and Y. Feng, "Frequency Control Strategy for Black Starts via PMSG-Based Wind Power Generation," Energies, vol. 10, no. 3, 2017, doi: 10.3390/en10030358.

[14] Wanggang, Zhaoyi, Sunfeng, Liuli, and Yepeng, "New wind storage power generation system black start control strategy research," in2014 China International Conference on Electricity Distribution (CICED) , 23-26 Sept. 2014 2014, pp. 1200-1206, doi: 10.1109/CICED.2014.6991897. 
[15] L. Li, S. Songjie, and W. Gang, "The control strategy research of wind power and storage based on the black start," in 2014 China International Conference on Electricity Distribution (CICED), 23-26 Sept. 2014 2014, pp. 979-982, doi: 10.1109/CICED.2014.6991850.

[16] Feng Sun, Yi Zhao, Gang Wang, and X. X. Lu, "Study on Charging and Discharging Characteristics of Energy Storage System in Wind Storage Power Plant under the Condition of Black Start," Advanced Materials Research, vol. 1070-1072, pp. 443-448, 2015.

[17] M. Aktarujjaman, M. A. Kashem, M. Negnevitsky, and G. Ledwich, "Black start with dfig based distributed generation after major emergencies," in 2006 International Conference on Power Electronic, Drives and Energy Systems , 12-15 Dec. 2006 2006, pp. 1-6, doi: 10.1109/PEDES.2006.344263.

[18] L. Sun, C. Peng, J. Hu, and Y. Hou, "Application of Type 3 Wind Turbines for System Restoration," IEEE Transactions on Power Systems, vol. 33, no. 3, pp. 3040-3051, 2018, doi: 10.1109/TPWRS.2017.2762009.

[19] Z. Alnasir and M. Kazerani, "An analytical literature review of stand-alone wind energy conversion systems from generator viewpoint," Renewable and Sustainable Energy Reviews, vol. 28, pp. 597-615, 2013/12/01/ 2013, doi: https://doi.org/10.1016/j.rser.2013.08.027.

[20] D. P. Kothari and I. J. Nagrath, Electrical Machines . Tata McGraw Hill, 2010.

[21] BinWu, Y. Lang, N. Zargari, and S. Kouro, "Generator Parameters," in Power Conversion and Control of Wind Energy Systems, I. Press, Ed.: John Wiley \& Sons, 2011, ch. Appendix B, pp. 319-326.

[22] R. Gagnon, "Wind Farm - DFIG Detailed Model (MATLAB/SIMULINK)," MATLAB/SIMULINK, Ed., ed.

[23] "IEEE Recommended Practice for Excitation System Models for Power System Stability Studies," IEEE Std 421.5-2016 (Revision of IEEE Std 421.5-2005), pp. 1-207, 2016, doi: 10.1109/IEEESTD.2016.7553421.

[24] A. B. Piardi, J. R. Pesente, R. B. Otto, and R. A. Ramos, "Evaluation of Volts/Hertz and over-excitation limiters acting under unbalanced load conditions," in 2013 IEEE Power \& Energy Society General Meeting , 21-25 July 2013 2013, pp. 1-5, doi: 10.1109/PESMG.2013.6672623.

[25] J. D. Hurley, "Underexcitation limiter models for power system stability studies," in IEEE Power Engineering Society General Meeting, 2005 , 16-16 June 2005 2005, pp. 980-984 Vol. 1, doi: 10.1109/PES.2005.1489401.

[26] G. Sybille and T. Z. (ETS), "Emergency Diesel-Generator and Asynchronous Motor,"

[27] C. W. G. 02, "Guidelines for representation of network elements when calculating transients," CIGRE 1990.

[28] S. D. Cho, "Parameter Estimation for Transformer modelling," PhD, Department of Electrical and Computer Engineering, Michigan Technical University, 2002.

[29] C. Ruiz, G. Abad, M. Zubiaga, D. Madariaga, and J. Arza, "Frequency-Dependent Pi Model of a ThreeCore Submarine Cable for Time and Frequency Domain Analysis," Energies, vol. 11, no. 10, 2018, doi: 10.3390/en11102778.

[30] P. Krause, O. Wasynczuk, S. Sudhoff, and S. Pekarek, "Symmetrical Induction Machines," in Analysis of Electric Machinery and Drive Systems, M. E. El-Hawary, Ed.: John Wiley \& Sons, 2013, ch. 6.

[31] R. C. Dugan, M. F. McGranaghan, S. Santoso, and H. W. Beaty, "Terms and Definitions," in Electrical Power Systems Quality, 2nd ed.: McGraw-Hill, 2004, ch. 2.

[32] "IEEE Recommended Practice-Adoption of IEC 61000-4-15:2010, Electromagnetic compatibility (EMC)-Testing and measurement techniques-Flickermeter-Functional and design specifications," IEEE Std 1453-2011, pp. 1-58, 2011, doi: 10.1109/IEEESTD.2011.6053977. 
[33] "IEEE Recommended Practice and Requirements for Harmonic Control in Electric Power Systems," IEEE Std 519-2014 (Revision of IEEE Std 519-1992), pp. 1-29, 2014, doi: 10.1109/IEEESTD.2014.6826459.

[34] D. K. Maina, M. J. Sanjari, and N. C. Nair, "Blackstart of DFIG-based Windfarm," in 2019 IEEE Power 83 Energy Society General Meeting (PESGM) , 4-8 Aug. 2019 2019, pp. 1-5, doi: 10.1109/PESGM40551.2019.8973876.

[35] T. V. Cutsem and C. Vournas, "Generation Aspects," in Voltage Stability of Electric Power Systems , T. A. Lipo and M. A. Pai Eds.: SPRINGER, 1998, ch. 3.

[36] A. M. Howlader and T. Senjyu, "A comprehensive review of low voltage ride through capability strategies for the wind energy conversion systems," Renewable and Sustainable Energy Reviews,vol. 56, pp. 643-658, 2016/04/01/ 2016, doi: https://doi.org/10.1016/j.rser.2015.11.073.
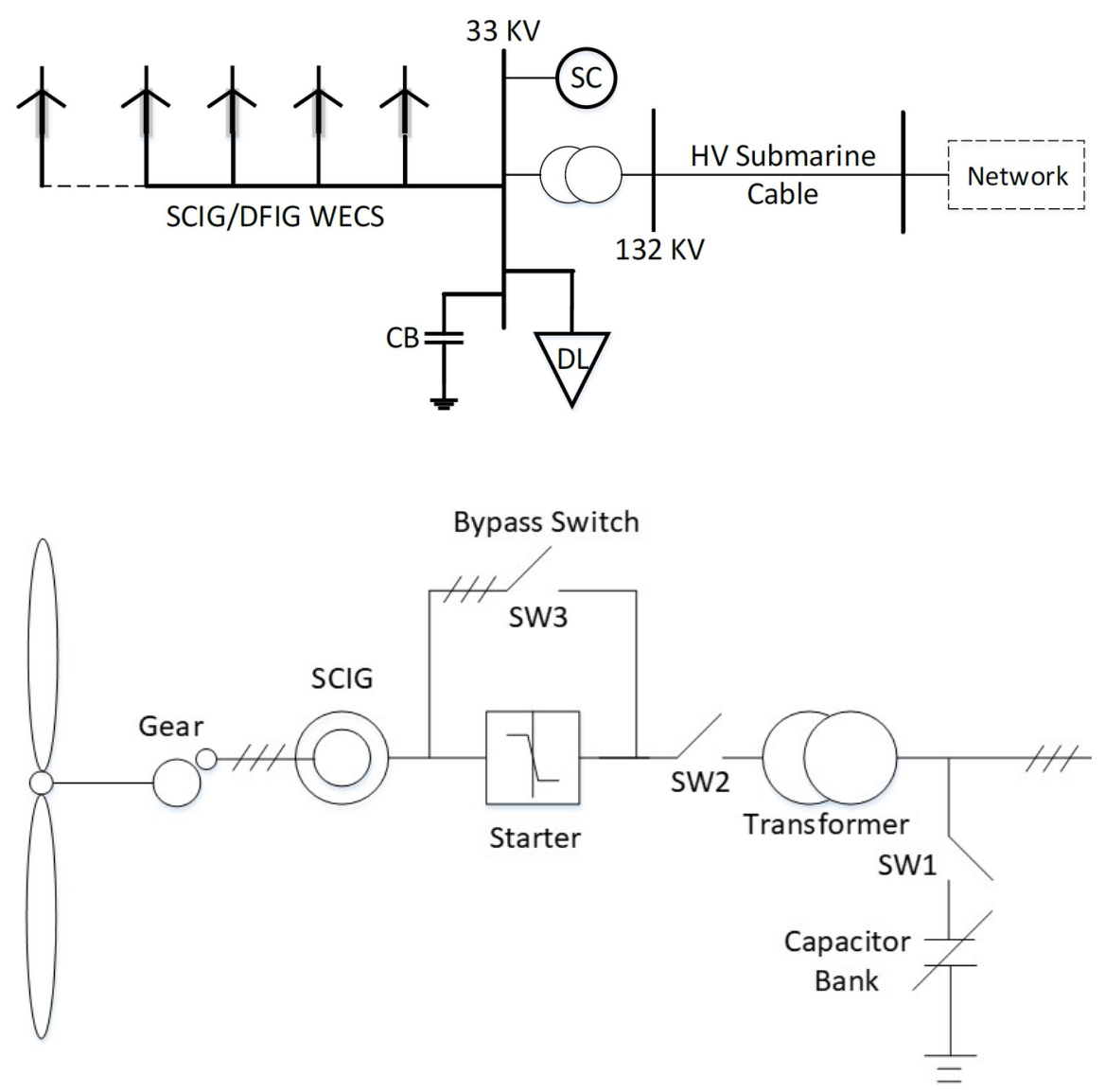

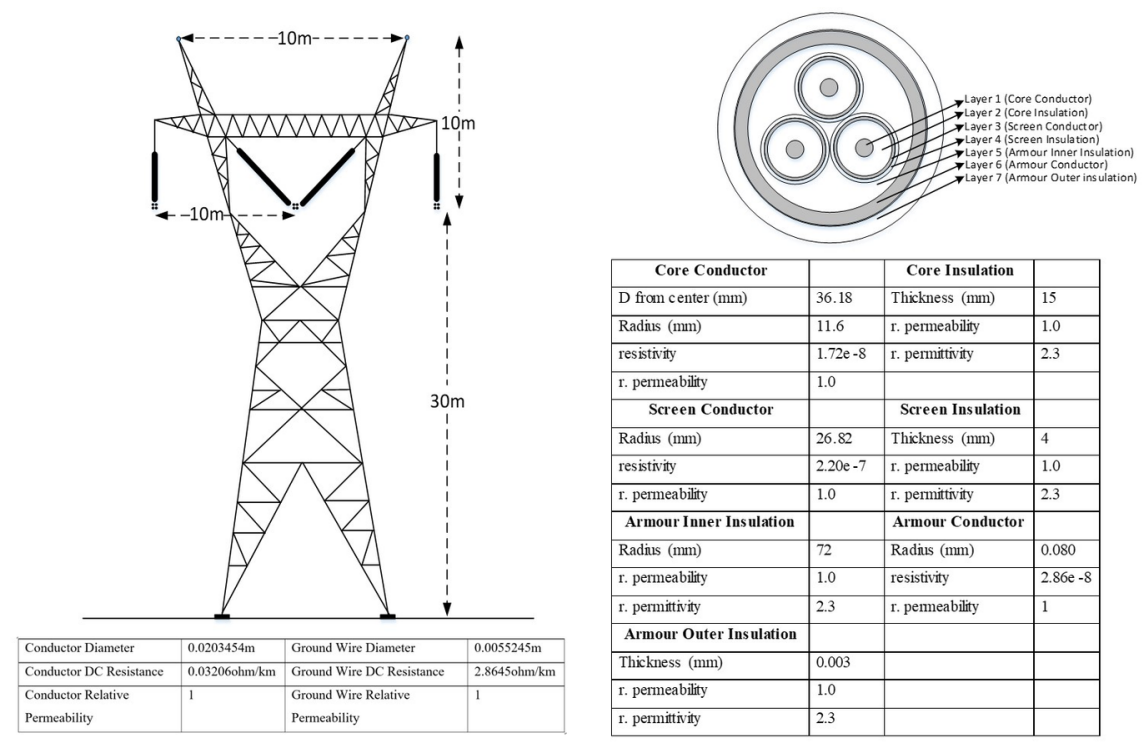

\begin{tabular}{|l|l|l|l|}
\hline \multicolumn{1}{|c|}{ Core Conductor } & & \multicolumn{1}{c|}{ Core Insulation } & \\
\hline D fram center (mm) & 36.18 & Thickness (mm) & 15 \\
\hline Radius (mm) & 11.6 & r. permeability & 1.0 \\
\hline resistivity & $1.72 \mathrm{e}-8$ & r. permittivity & 2.3 \\
\hline r. permeability & 1.0 & & \\
\hline \multicolumn{1}{|c|}{ Screen Conductor } & & Screen Insulation & \\
\hline Radius (mm) & 26.82 & Thickness (mm) & 4 \\
\hline resistivity & $2.20 \mathrm{e}-7$ & r. permeability & 1.0 \\
\hline r. permeability & 1.0 & r. permittivity & 2.3 \\
\hline Armour Inner Insulation & & Armour Conductor & \\
\hline Radius (mm) & 72 & Radius (mm) & 0.080 \\
\hline r. permeability & 1.0 & resistivity & $2.86 \mathrm{e}-8$ \\
\hline r. permittivity & 2.3 & r. permeability & 1 \\
\hline Armour Outer Ins ulation & & & \\
\hline Thickness (mm) & 0.003 & & \\
\hline r. permeability & 1.0 & & \\
\hline r. permittivity & 2.3 & & \\
\hline
\end{tabular}
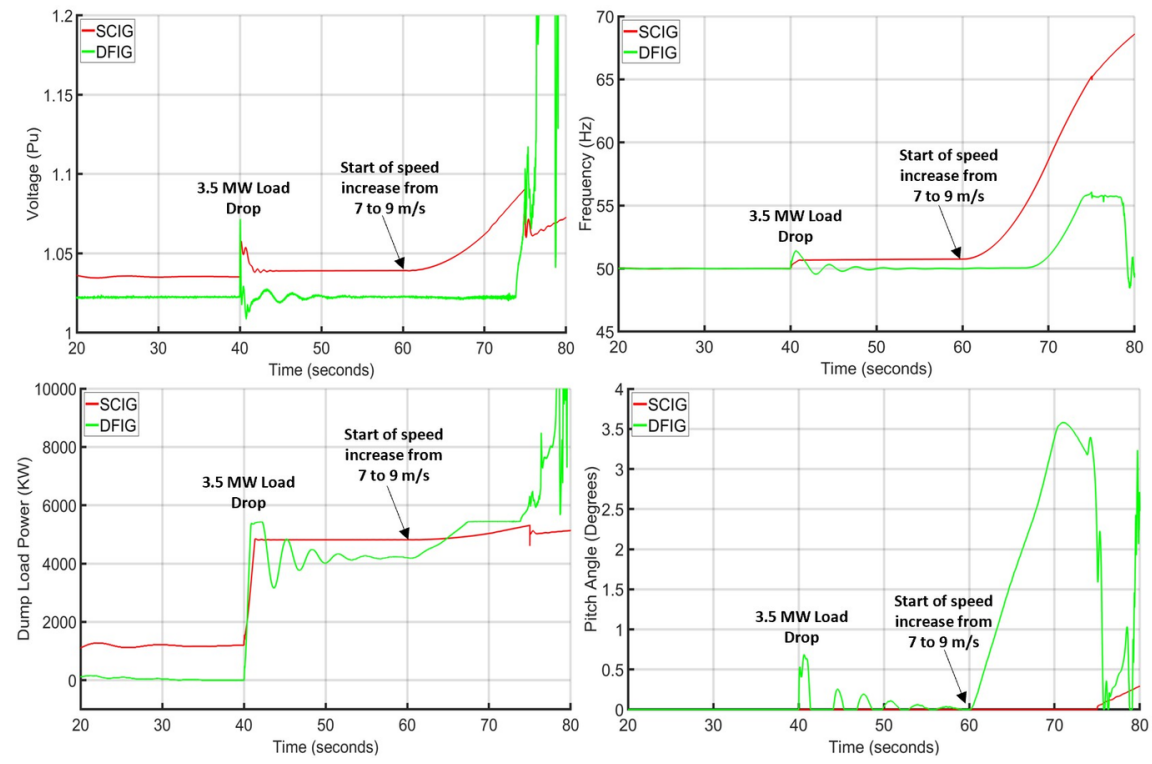

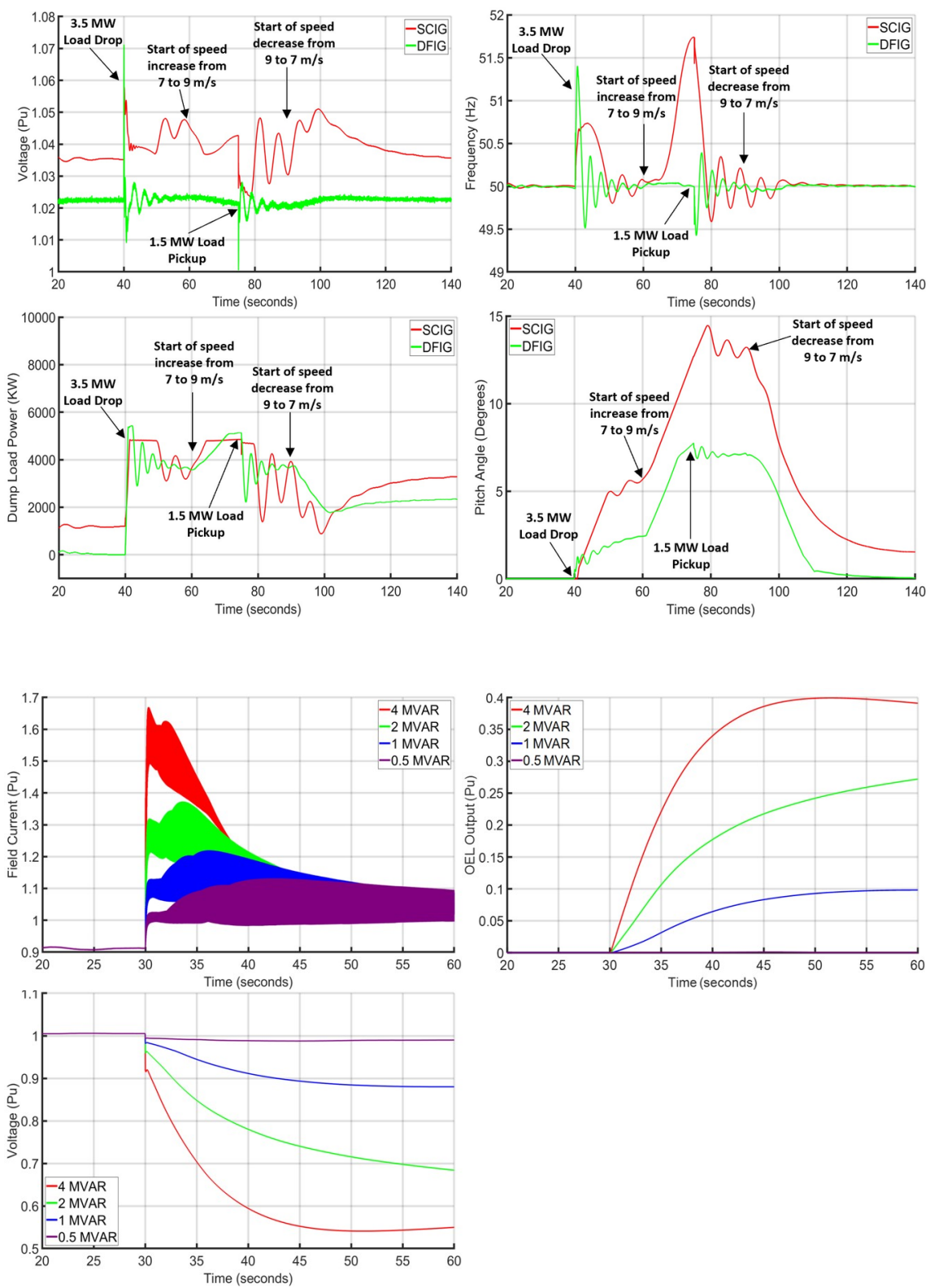

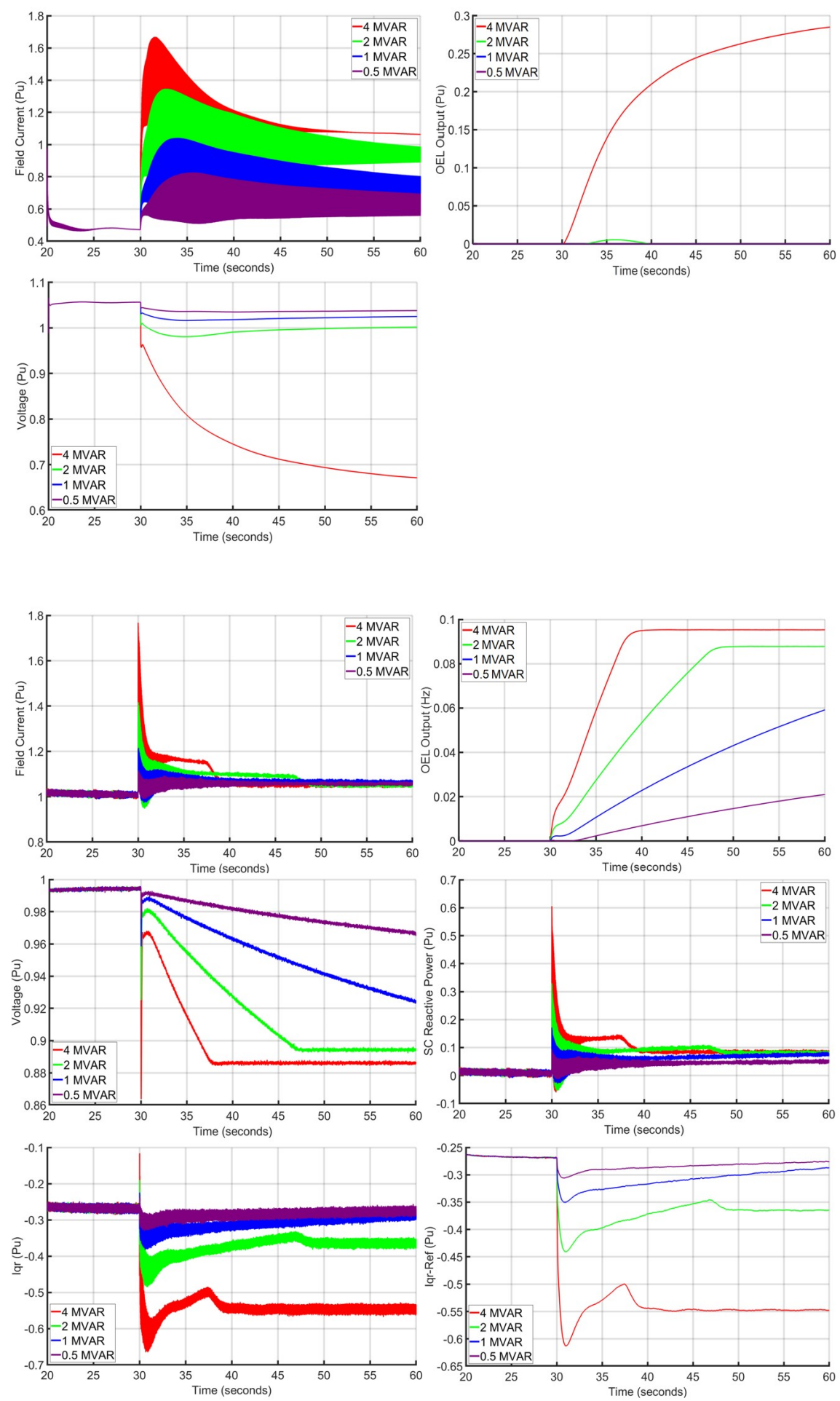

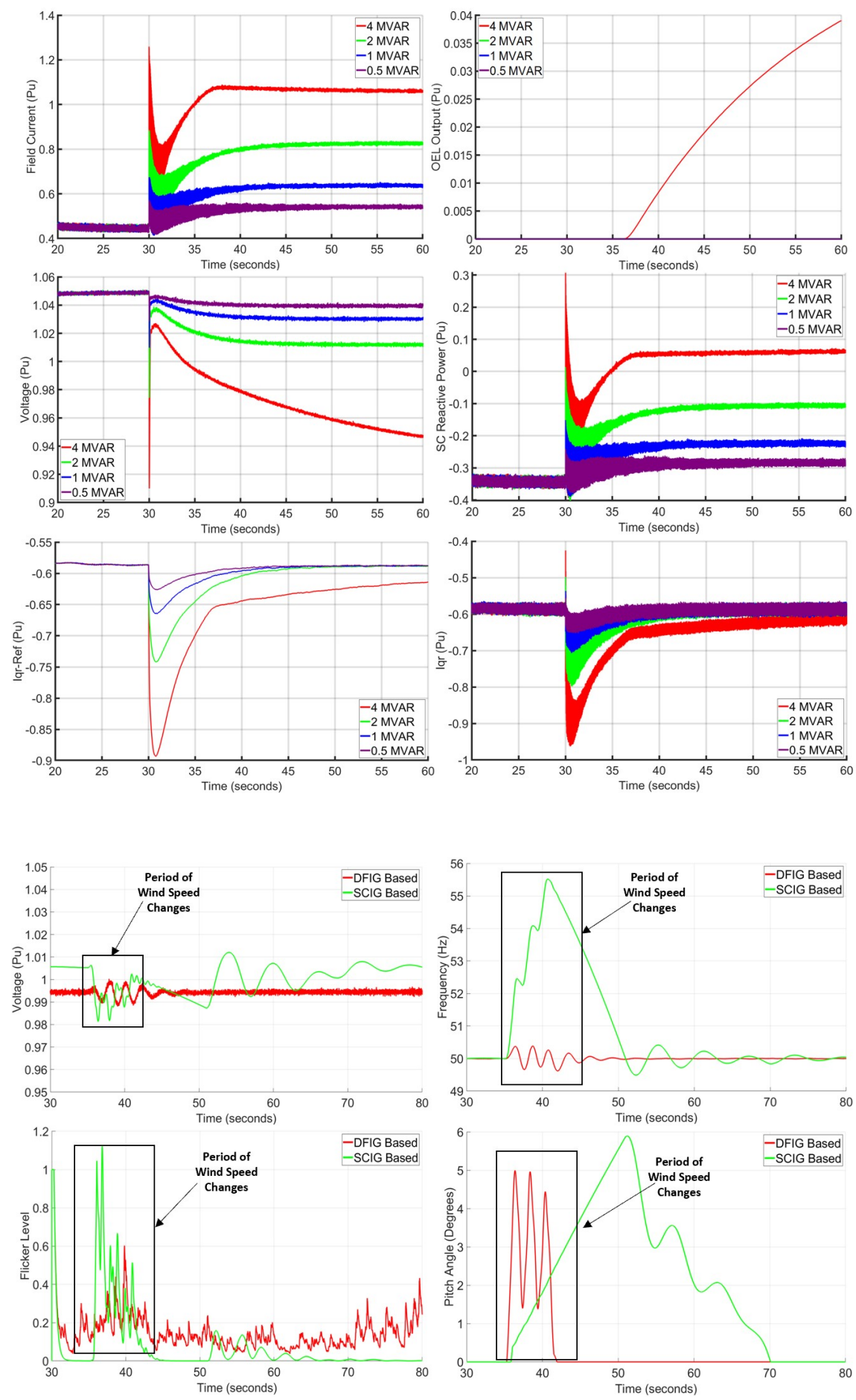

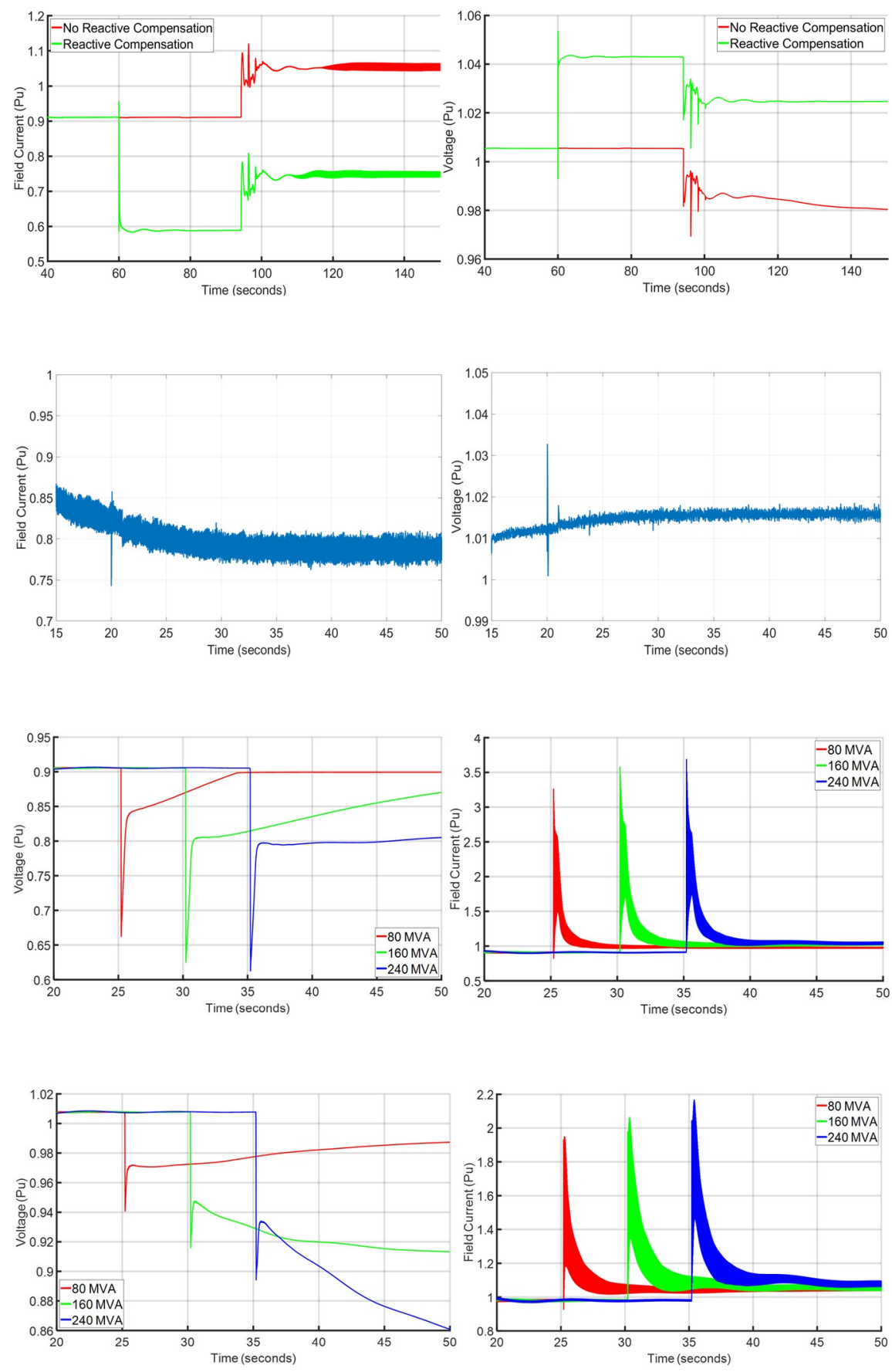

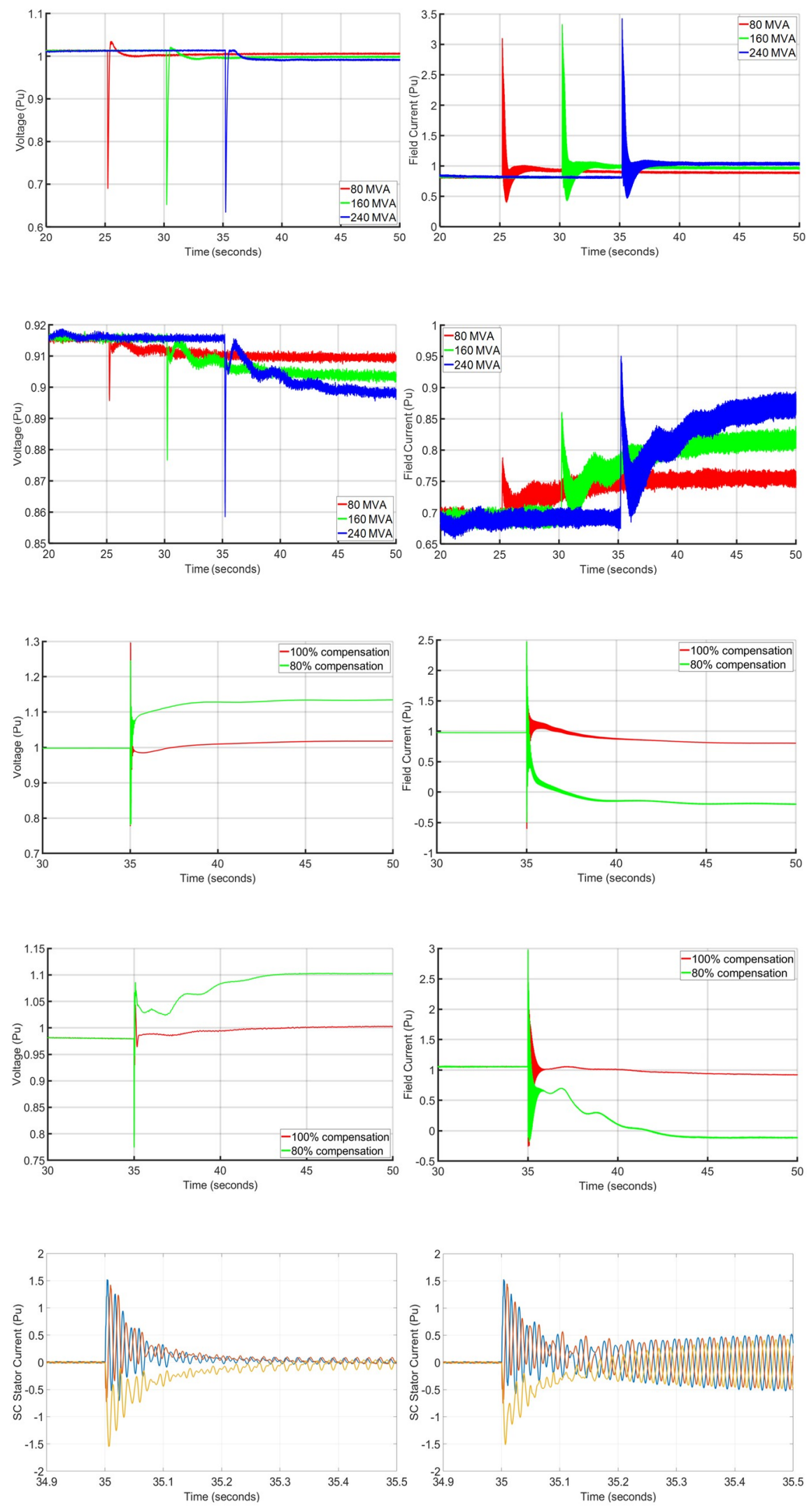

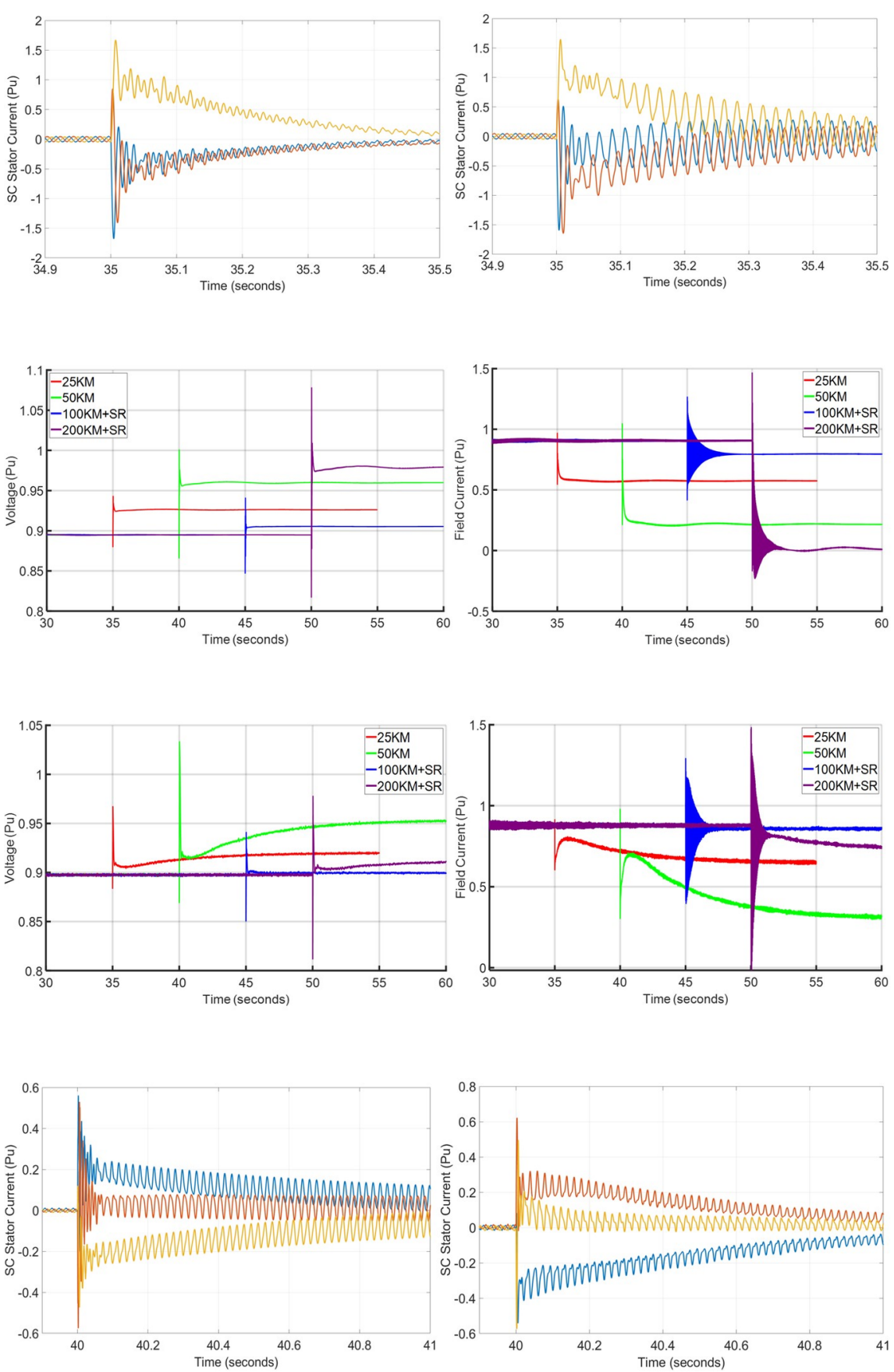

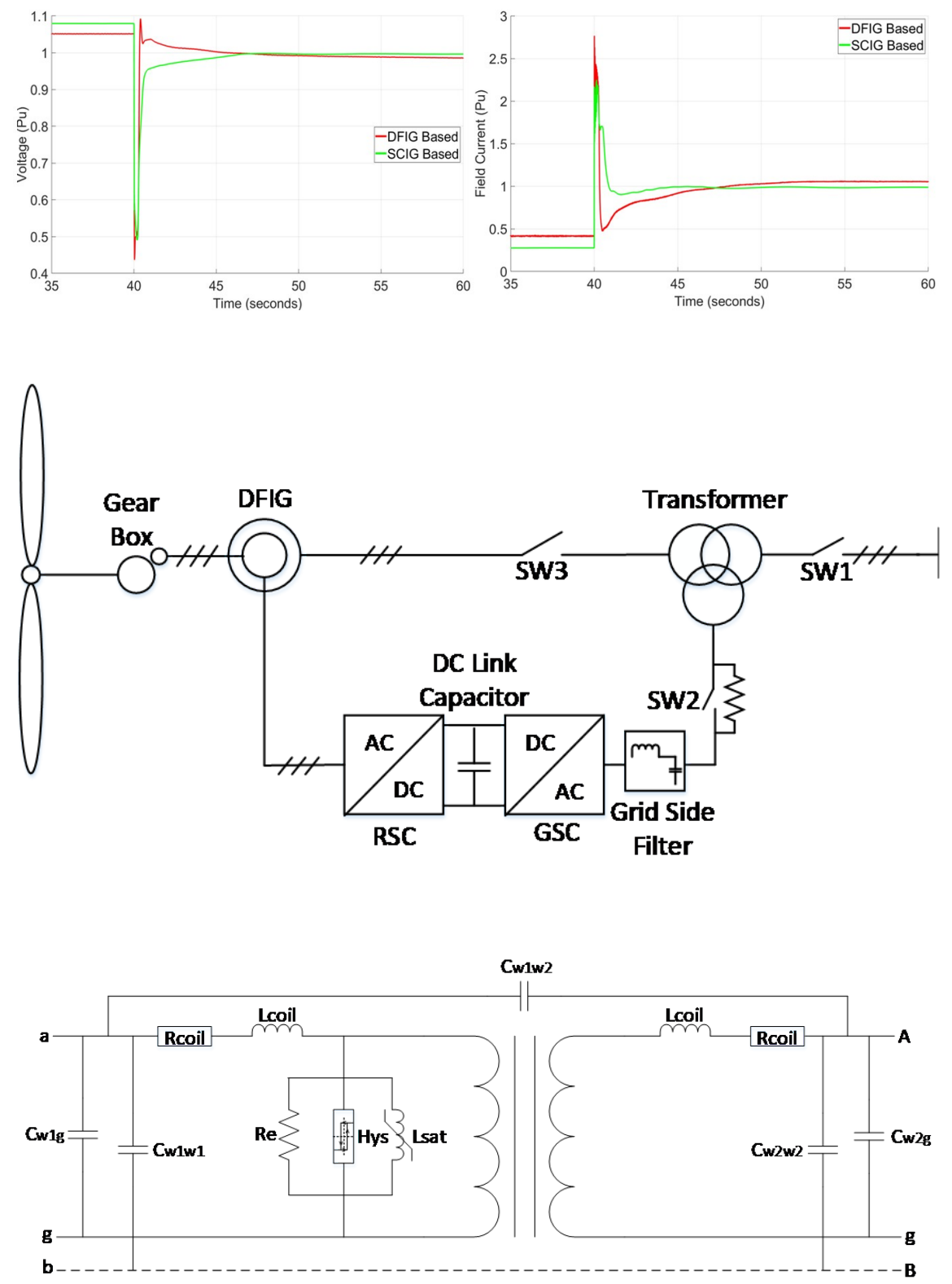

\section{Hosted file}

Table 1_THD for both SCIG and DFIG based Hybrid System.pdf available at https://authorea.com/ users/393037/articles/506769-study-on-re-energization-capability-of-a-hybrid-windfarmunder-a-microgrid-based-restoration-strategy 